NBER WORKING PAPER SERIES

\title{
TEMPORARY UNEMPLOYMENT AND LABOR MARKET DYNAMICS DURING THE COVID-19 RECESSION
}

\author{
Jessica Gallant \\ Kory Kroft \\ Fabian Lange \\ Matthew J. Notowidigdo \\ Working Paper 27924 \\ http://www.nber.org/papers/w27924 \\ NATIONAL BUREAU OF ECONOMIC RESEARCH \\ 1050 Massachusetts Avenue \\ Cambridge, MA 02138 \\ October 2020
}

This paper was prepared for the September 2020 Brookings Papers on Economic Activity conference. We thank Gabrial Chodorow-Reich, Lawrence Katz, and David Romer for comments and suggestions, and we thank Eliza Forsythe, Lisa Kahn, and David Wiczer for very helpful conversations surrounding some of the same issues of temporary unemployment. We also thank Jiahao Chen and Jeremy Mopsick for excellent research assistance and Alissa Aviles and Grace $\mathrm{Su}$ for reviewing our conference draft. The views expressed herein are those of the authors and do not necessarily reflect the views of the National Bureau of Economic Research.,

NBER working papers are circulated for discussion and comment purposes. They have not been peer-reviewed or been subject to the review by the NBER Board of Directors that accompanies official NBER publications.

(C) 2020 by Jessica Gallant, Kory Kroft, Fabian Lange, and Matthew J. Notowidigdo. All rights reserved. Short sections of text, not to exceed two paragraphs, may be quoted without explicit permission provided that full credit, including $\odot$ notice, is given to the source. 
Temporary Unemployment and Labor Market Dynamics During the COVID-19 Recession Jessica Gallant, Kory Kroft, Fabian Lange, and Matthew J. Notowidigdo NBER Working Paper No. 27924

October 2020

JEL No. J01,J11,J64

\begin{abstract}
$\underline{\text { ABSTRACT }}$
This paper develops a search-and-matching model that incorporates temporary unemployment and applies the model to study the labor market dynamics of the COVID-19 recession in the US. We calibrate the model using panel data from the Current Population Survey for 2001-2019, and we find that the model-based job finding rates match observed job finding rates during the entire sample period and out-of-sample up through July 2020. We also find that the Beveridge curve is well-behaved and displays little change in market tightness in 2020 once we use the calibrated model to adjust for changes in the composition of the unemployed. We then use the model to project the path of unemployment over the next 18 months. Under a range of assumptions about job losses and labor demand, our model predicts a more rapid recovery compared to a model that does not distinguish between temporary and permanent unemployment and compared to professional and academic forecasts. We find that in order to rationalize the professional forecasts of the unemployment rate, some combination of the vacancy rate, job separation rate, and recall rate of workers on temporary layoff must deteriorate substantially from current levels in the next several months.
\end{abstract}

Jessica Gallant 150 St George St

Toronto, ON M5S 3G7

CANADA

jessica.gallant@mail.utoronto.ca

Kory Kroft

Department of Economics

University of Toronto

150 St. George Street

Toronto, ON M5S 3G7

CANADA

and NBER

kory.kroft@utoronto.ca
Fabian Lange

Department of Economics

McGill University

855 Sherbrooke Street West

Montreal QC H3A, 2T7

and NBER

fabian.lange@mcgill.ca

Matthew J. Notowidigdo

Northwestern University

Department of Economics

2001 Sheridan Road

Evanston, IL 60208-2600

and NBER

noto@northwestern.edu

A data appendix is available at http://www.nber.org/data-appendix/w27924

A Brookings summary is available at

https://www.brookings.edu/bpea-articles/temporary-unemployment-and-labor-market-dynamics-during-thecovid-19-recession/

A Video presentation is available at

https://www.youtube.com/watch?time_continue=1\&v=4Uod9qnZ7Uo\&feature= 
In the aftermath of the 1991-1992 recession, the economist Benjamin Friedman discussed the "Tolstoian notion that while expanding economies are all alike, every contracting economy is contracting in its own way." 1 The notion of course is an exaggeration (in fact, Friedman wrote that the early 1990s contraction "was pretty much like other contractions"), but some recessions are unusual, and the COVID-19 recession is one of the most unusual recessions in a very long time.

What makes the COVID-19 recession unique is the nature of the initial shock. While past recessions have been primarily caused by economic or financial shocks, the adverse shock to the labor market in 2020 was biological in nature, triggered by a novel virus that forced millions of employees into temporary unemployment by the second quarter of 2020. The record-level rise in temporary unemployment contrasts starkly with past recessions that typically start with an increase in permanent layoffs (Elsby et al., 2010). The path of job vacancies has also been unusual: while vacancies fell throughout the first half of 2020, the drop was much less pronounced than is typical in most recessions. In fact, vacancies at their lowest level were equal to the level that prevailed in 2015, a time typically considered to be a tight labor market. Thus, while the Beveridge curve - the negative relationship between vacancies and unemployment typically "loops around" during and after a recession, in the early months of the COVID-19 recession, the increase in the unemployment rate was much larger than the corresponding drop in job vacancies. ${ }^{2}$

The unusual nature of the COVID-19 recession makes it difficult to draw on experiences from past recessions to project how the labor market will evolve in the months ahead. For example, during the Great Recession, the initial wave of layoffs was subsequently followed by a prolonged period of lower job finding rates (Elsby, 2009; Elsby et al., 2011). This led to a significant increase in the long-term unemployment share, which in turn prolonged the recession through negative duration dependence (Kroft et al., 2016; Krueger et al., 2014). Currently available data suggest that the dynamics of the COVID-19 recession may play out quite differently. In particular, vacancies continue to be elevated, and job finding rates have not decreased substantially - both the recall rates for the temporary unemployed, as well as the job finding rates for workers who have been permanently laid off.

In this paper, we develop a "flows-based approach" to shed light on the key economic forces affecting the labor market. The key building blocks of our model are the transitions between

\footnotetext{
${ }^{1}$ This quote comes from Professor Friedman's discussion of the Schultze and Perry paper in the 1993 Brookings Papers on Economic Activity titled "Was This Recession Different? Are They All Different?"

${ }^{2}$ The journalist Catherine Rampell colorfully commented on Twitter that the "Beveridge curve is drunk."
} 
labor market states, some of which we take to be exogenous (e.g., separation rates) and some of which we model endogenously (e.g., job finding rates). While the typical approach to studying the labor market considers three states - employment, unemployment and non-participation our model further divides unemployment into "temporary unemployment" and "permanent unemployment." The importance of temporary unemployment for the current downturn has been widely commented on and also features heavily in the work by Chodorow-Reich and Coglianese (2020). Similarly, Forsythe et al. (2020b) emphasize the importance of this distinction for understanding current trends in the labor market and specifically observed levels of market tightness. In particular, Forsythe et al. (2020b) point out that it is necessary to separate the temporary unemployed from those searching for jobs when considering the performance of the matching market.

To be very clear at the outset, by "permanent unemployment" we do not mean to imply that individuals in this state are permanently unemployed; rather, individuals in this state have been permanently separated from their former employer. Similarly, by "temporary unemployed," we mean individuals who have been temporarily separated from their employer and are expecting to be recalled. ${ }^{3}$

We argue that the distinction between temporary and permanent unemployment is crucial for understanding the dynamics of the COVID-19 recession for several reasons. First, the temporary unemployed historically find jobs at much higher rates than the permanent unemployed. Second, we argue that the temporary unemployed who are waiting to be recalled do not affect the tightness of the labor market in the same way as those who have been permanently separated and are actively searching for work. In particular, individuals who are actively searching for a job reduce the chance that other job seekers are employed, as they compete for the same job openings. In this sense, job search "congests" the labor market, and our model captures this distinction between temporary and permanent unemployment by allowing for the job finding rates of active searchers to depend on market tightness. In our model, the group of temporary unemployed is made up of some who are "waiting" to be recalled and thus not searching for a job, and others who are "actively searching" just like other unemployed workers who have been permanently laid off.

Our model also allows for negative duration dependence, whereby job finding probabilities decline with unemployment duration. Thus, it can shed light on whether duration dependence, when combined with the massive wave of layoffs in March and April 2020, will lead to

\footnotetext{
${ }^{3}$ According to these definitions, temporary unemployed individuals can become permanently unemployed if they are not recalled and are eventually laid off permanently, and our model allows for this possibility.
} 
"scarring" effects in the labor market. Formally, duration dependence enters into the model in two ways. First, job finding probabilities for both temporary and permanent unemployed individuals will vary with unemployment duration. Second, the model permits individuals to transition from temporary unemployment to permanent unemployment (and vice versa) over time, which implies that the overall job finding rate from unemployment can exhibit negative duration dependence due to compositional effects.

We calibrate our model using panel data from the Current Population Survey for 2001-2019. We find it closely matches job finding rates for both temporary unemployed and permanent unemployed during the entire sample period, and it also matches job finding rates out-of-sample up through July 2020. By contrast, the model in Kroft et al. (2016), which does not distinguish between temporary and permanent unemployment, performs much worse out-of-sample in 2020. In particular, the off-the-shelf model substantially under-predicts the overall job finding rates of the unemployed starting in April 2020. As we discuss in more detail below, this reflects the fact that the Kroft et al. (2016) model would predict substantial "congestion" from a large number of unemployed workers chasing a limited number of vacancies. This would substantially reduce market tightness, which would in turn reduce the predicted job-finding rate relative to observed job finding rates. Since the model in this paper accounts for temporary unemployment, and many of the unemployed are temporary unemployed, we are able to match the overall job-finding rates of the unemployed very closely, even out-of-sample up through July 2020.

Since the calibrated model fits well out-of-sample during the first several months of the COVID-19 recession, we use it to shed light on several economic phenomena. First, we use the model to study the Beveridge curve in 2020. Using the calibrated model, we find that the Beveridge curve is well-behaved and displays little change in market tightness in 2020, once we adjust for changes in the composition of the unemployed. ${ }^{4}$ In other words, we conclude that temporary unemployment is key to understanding the apparently-puzzling movement in the Beveridge curve this year, which destroyed the historical relationship between vacancies and unemployment. Through the lens of our calibrated model, the temporary unemployed include many individuals not actively searching, which means they should not contribute very much to the measure of unemployment used to indicate labor market tightness. This analysis helps understand the recent survey responses from workers who do not perceive that it is difficult to find a job, even when the headline unemployment rate was above 10 percent (The Conference Board, 2020). According to our model, jobs are not "scarce" for the relatively small share of unemployed workers who are actually searching for a job.

\footnotetext{
${ }^{4}$ See also Forsythe et al. (2020b).
} 
Second, we simulate the calibrated model for the next 18 months to predict changes in the unemployment rate. We do this by considering a range of paths for the exogenous forcing variables such as separation rates, job vacancies, and recall rates for the temporary unemployed who are "waiting" (and not actively searching). In our baseline scenario, we assume that the forcing variables steadily converge to their "normal" values over the next 24 months. Our calibrated model predicts a more rapid recovery compared to the Kroft et al. (2016) model that does not distinguish between temporary and permanent employment, and predicts a more rapid recovery than professional forecasts. We also find little increase in long-term unemployment (relative to the levels that prevailed prior to the start of the COVID-19 recession). We then look at additional scenarios and conclude that in order to rationalize existing professional forecasts of the unemployment rate, the labor market would have to deteriorate substantially, with either job separation rates increasing by over 50 percent over the coming months, or job vacancies decreasing by the same magnitude over the coming months.

Overall, we conclude that our model provides some rigorous support for focusing somewhat less on the "headline" unemployment rate as a measure of labor market slack during the COVID19 recession. Instead, our preferred measure of slack takes into account the composition of the unemployed; in particular, it accounts for the distinction between temporary and permanent unemployment, the share of the temporary unemployed who are actively searching, and the distinction between short-term and long-term unemployment. Importantly, each group imposes a different degree of "congestion" on the labor market. Along with standard measures of labor demand, such as job vacancies and the separation rate, our model provides a relatively complete picture of the health of the labor market and can provide useful guidance to forecasting labor market dynamics in the aftermath of the COVID-19 recession. This will be a useful guide to policymakers who are continuing to debate appropriate stimulus policies, such as the Paycheck Protection Program (PPP) and the \$600 Unemployment Insurance supplement.

The remainder of this paper proceeds as follows: Section I provides a brief review of the related literature on temporary unemployment and the recall expectations of unemployed workers, and it also discusses broadly related recent work studying the COVID-19 recession. Section II discusses the data and measurement, and presents figures that motivate the model-based analysis. Section III describes our new search-and-matching model with temporary unemployment and goes through the calibration of the model. Section IV describes how we use the calibrated model to adjust for changes in the composition of the unemployed and how this results in a well-behaved Beveridge curve that displays little change in market tightness throughout 2020. Section V presents the counterfactual simulations that predict the unemployment rate and other 
labor market statistics over the next 18 months under different scenarios. Section VI concludes.

\section{Related Work}

The sharp downturn in the labor market starting in 2008 and the long slow recovery that followed motivated a series of papers on the flows across labor force states and how they contributed to the slow recovery in the aftermath of the Great Recession. This paper builds on this literature, which we selectively describe in this section.

In two contributions to the Brookings Papers on Economic Activity, Elsby et al. (2010) and Elsby et al. (2011) characterize the dynamics of recessions, including the Great Recession, in terms of unemployment inflow and outflow rates. Elsby et al. (2010) write: "In all recessions, inflows account for a substantial fraction of unemployment variation early on and then subside. In contrast the contribution of the outflow rate becomes more dominant as each recession progresses" (pp. 18-19). They show that during the Great Recession, the decline in the outflow rate from unemployment was particularly sharp, leading the labor market to contract over a particularly long time period and long-term unemployment to increase to levels not seen during the post-war period.

In Kroft et al. (2016), three of us (along with Lawrence Katz, "KLNK") responded to the increase in long-term unemployment by analyzing how duration dependence in job finding rates and congestion from the unemployed and non-participants contributed to the build-up in long-term unemployment and the slow recovery of the labor market during and after 2009. While the current paper owes much of its analytic structure to KLNK, it also recognizes, as do Chodorow-Reich and Coglianese (2020) and Forsythe et al. (2020b), how important temporary unemployment is for the current downturn and thus augments the model to allow for temporary unemployment. ${ }^{5}$

The importance of accounting for temporary unemployment when modeling transition dynamics in the labor market was noted previously by Katz (1986), Katz and Meyer (1990), and Lilien (1980). More recently, Fujita and Moscarini (2017) reconsider the evidence on temporary unemployment and find that it is pervasive, even in normal times, since many individuals who began their unemployment spell in permanent unemployment eventually return to their former employers.

Additionally, our model emphasizes (negative) duration dependence in job finding proba-

${ }^{5}$ Krueger et al. (2014) and Kroft et al. (2019) build on KLNK and calibrate similar search-and-matching models. 
bilities, consistent with empirical evidence from Katz (1986) and Fujita and Moscarini (2017) on duration dependence in job finding rates among the temporary unemployed. ${ }^{6}$

While we do not observe whether a worker is recalled by their former employer directly in our data, we find - consistent with Katz and Meyer (1990) - that the temporary unemployed have higher re-employment rates, even if they do not report that they are actively searching for a job. As Forsythe et al. (2020b) point out, the temporary unemployed (as compared to the permanent unemployed) are more likely to be hired into the same industry as before their unemployment spell. This is what we would expect if these individuals were recalled to their former employer at a higher rate than the permanently unemployed.

Our paper complements other recent research studying labor market dynamics during the COVID-19 recession. In particular, Chodorow-Reich and Coglianese (2020) study unemployment durations using CPS data. Similar to our model, they also allow for temporary unemployment, but they also differentiate between layoffs and quits as well as labor market entrants among the unemployed. They take a factor-flows simulations approach and assume the overall unemployment rate is an observed factor, while we allow the unemployment rate to evolve endogenously using the structure of the matching model and a pre-specified path of job vacancies and separations. Despite the differences in methodology, both papers find little reason to expect long-term unemployment to come close to the levels observed during the Great Recession. ${ }^{7}$

Lastly, there are a large number of papers studying the recent economic turmoil during the COVID-19 recession. We can only selectively review these papers here. Bartik et al. (2020b) study small business expectations towards the start of the recession and find that business expectations are closely tied to the firm's "cash on hand." When businesses are told about PPP loans, the businesses are more likely to report that they expect to be able to remain open. Bartik et al. (2020a) and Forsythe et al. (2020a) find that state variation in stay-at-home orders had little effect on economic activity. ${ }^{8}$ One interpretation is that rising concerns about

\footnotetext{
${ }^{6}$ While these papers find negative duration dependence is mostly driven by the recall rates of the temporary unemployed, Nekoei and Weber (2015) find somewhat contradictory evidence that negative duration dependence only occurs when recalls are excluded from the unemployed pool.

${ }^{7}$ Additionally, our paper is broadly related to Gregory et al. (2020), which develops an equilibrium model of job search allowing for unemployed workers to be recalled to their former employer. Their primary objective was to forecast the path of COVID-19 recession in response to the lockdown, based on information available in May 2020. We predict a more rapid recovery than they did, which we think is because observed rates of temporary unemployment and recall rates are significantly higher than those anticipated by Gregory et al. (2020). Methodologically, our approach is more "reduced form" than the equilibrium model of Gregory et al. (2020), and they rely on LEHD and SIPP data, while we use CPS data which allows us to measure the duration structure of unemployment and the breakdown between temporary and permanent unemployment, as well as non-participation.

${ }^{8}$ We build on Forsythe et al. (2020a) - and follow-up work by the same authors that is currently not circulating - in terms of how we classify the labor force across labor force states.
} 
public safety led to sharp decrease in demand for in-person services, whether or not a stayat-home order was in place. This interpretation is consistent with data on individual mobility in Goolsbee and Syverson (2020), who conclude that voluntary changes in behavior played a larger role than government policies. Lastly, Barrero et al. (2020) study job reallocation during the COVID-19 recession and document "excess" job reallocation using survey data on expected job gains across industries.

\section{Data, Measurement, and Motivating Evidence}

\section{II.A. Data}

We use the same data sources as Kroft et al. (2016), updated to the most recent month available. The Appendix provides more details on the data used in our analysis, and some of the discussion below follows Kroft et al. (2016).

\section{CURRENT POPULATION SURVEY (CPS)}

We use monthly CPS data between January 2001 and August 2020, limiting the sample to individuals between the ages of 25 to $55 .{ }^{9}$ We use the CPS data in several ways. First, we use the repeated cross-sectional data to measure the "stocks" of each labor market state each month: employment, temporary unemployment, permanent unemployment, and nonparticipation. Second, we use the panel structure of the CPS to measure month-to-month transition rates between states, such as the job finding rate or transition rates between temporary and permanent unemployment, for example. ${ }^{10}$ We also measure the duration of the unemployment spell, which allows us to estimate transition rates conditional on unemployment duration.

${ }^{9}$ Following Kroft et al. (2016), we focus on prime-age men and women since this allows us to sidestep issues arising from delayed labor force entry of younger workers and changes in retirement patterns of older workers. Appendix Figure OA.16 shows that the "headline" unemployment rate from the BLS very closely tracks our unemployment rate measure in this paper, which is based on the age 25-55 prime-age sample restriction and also includes individuals employed but absent from work for other reasons as part of the temporary unemployed, as we discuss in more detail below.

${ }^{10}$ The CPS interviews households for two four-month spells spaced apart by eight months. To create panel data, we match individual observations across successive months, matching on household identifier, line number, age, gender, and race. 


\section{JOB OPENINGS AND LABOR TURNOVER SURVEY (JOLTS)}

We use the total number of vacancies from monthly JOLTS data between January 2001 and July 2020, and we use the vacancy data through December 2019 to calibrate the matching model described below. We then use the 2020 vacancy data as one of the exogenous "forcing variables" to assess how well the calibrated model fits out-of-sample during 2020.

\section{II.B. Measurement}

In recent months, common labor market indicators have at times moved in dramatic fashion. These movements occurred during a unique moment when many workers were asked to stay at home and others were afraid to go to work. The measurement framework of the BLS was not designed with such an event in mind, but instead was meant to track the performance of the labor market across less unusual business cycles. In this Section, we describe how we adapt the data from the CPS to confront the challenges of adequately capturing the distinction between waiting to be recalled by a former employer and searching for a new employer. Our approach to mapping the CPS questions into the categories of waiting and searching derives from Forsythe et al. (2020b). We note at the outset that the CPS data does not directly measure ex post recall - i.e., whether an individual who transitions from temporary unemployment to employment returns to their former employer.

\section{STOCKS}

We begin by discussing how we measure the distribution of the workforce across labor force states. This measurement framework draws heavily on Forsythe et al. (2020b), who are likewise using the CPS monthly data and confronting the same problems of characterizing how connected the unemployed are to their former employers and the labor market.

Temporary unemployment plays an important role in our analysis below. However, the traditional way of defining temporary unemployment in the CPS does not fully capture the extent to which layoffs were temporary during the COVID-19 recession. Forsythe et al. (2020b) propose using the more detailed questions on labor force participation in the CPS to classify respondents into whether they are waiting to be re-employed, or whether they are actively searching for job. They aim to measure who is most likely to be searching for matches with new employers and who is instead more likely hoping to return to their previous employer.

Compared to the typical employed-unemployed-out of the labor force categorization, Forsythe et al. (2020b) in addition introduce a category of those who are temporarily unemployed but 
not searching for work and those who report being absent from work without pay. ${ }^{11} 12$ They base these decisions on the wording of the questions in the CPS and on guidance provided by the BLS regarding the survey during the pandemic. Additionally, Forsythe et al. (2020b) are guided by the evidence from job finding patterns among those employed in February and March and non-employed in April. They find that the group consisting of those temporary unemployed not searching or absent without pay are more likely to return to the same industry when they are reemployed than the permanently unemployed. Among those searching for work, those on temporary layoff but searching have a higher likelihood of returning to the same industry than the permanently unemployed (but lower than those on temporary layoff and not searching).

We follow Forsythe et al. (2020b) in our approach to classifying individuals, except for separately considering the temporary unemployed that are actively searching. There are specific groups that require attention. Throughout, we rely on their evidence of whether "April separators" return to the same industry to motivate our data choices.

The first group to consider are those who report that they are employed, but are absent from work. Roughly 1.5-2 percent of the population normally falls into this category. The CPS asks these individuals to provide specific reasons for their absence such as vacation time, child care, training, etc. During normal times, only about 10-15 percent of those absent from work fall into the residual category of other "unspecified reasons." Between February and April 2020, however, the share absent from work for unspecified reasons ballooned to 2.4 percent of the population. The BLS has reported that "analysis of the underlying data suggests that this group includes workers affected by the pandemic who should be classified as unemployed on temporary layoff" (BLS, 2020). The data on "April separators" (see Forsythe et al. (2020b)) also show that roughly 19 out of every 20 in this group return to their former industry, suggesting that individuals in this group are very likely to return to work at their former workplaces. For these reasons, we assign the entire group of "employed but absent for other reasons and unpaid" to the temporary unemployed in all of our analysis.

During the Spring 2020, we also note an unusual rise in the number of those not in the labor force but are neither retired or disabled. Between February and April, the share of this group in the population rose from 13.2 to 16.5 percent. We speculate that some of this increase is due to the fluid boundary between non-participation and unemployment. In particular, the

\footnotetext{
${ }^{11}$ They call this group the "waiting room" and distinguish them from the "open market" which consists of those actively searching, whether or not they report being on temporary unemployment.

${ }^{12}$ The BLS has reported that "analysis of the underlying data suggests that this group [those absent form work without pay] includes workers affected by the pandemic who should be classified as unemployed on temporary layoff" (BLS, 2020).
} 
data indicate increased "churning" between non-participation and temporary unemployment during the pandemic. And, the share of those recalled to their industry among April separators who are not in the labor force (and want a job and are not searching) mirrors that of the temporary unemployed. Thus, it seems plausible that some of the individuals transitioning from employment to being not in the labor force are really temporarily unemployed but do not report it that way. Allocating the entire group due to the increase of 3 percentage points to temporary unemployment, however, would also mean allocating the roughly 13 percent that form the base of this group even outside of pandemic times to temporary unemployment. It is therefore not possible for us to get a time-consistent way of classifying these individuals that relies only on current responses to the CPS. As a result, we retain this group among those not in the labor force but flag that in April and May 2020 this population consists (to an unusual degree) of individuals closely attached to the labor market, who are expecting to return to work shortly. ${ }^{13}$

Next, we divide the temporary unemployed based on their answer to the question about whether they are "actively searching" for a new job while on temporary unemployment. We believe that those actively searching for a job contribute to congestion in the search labor market, while those who are not actively searching are instead "waiting" to return to work and thus do not contribute to congestion. Empirically, the job finding rates between these two groups of the temporary unemployed differ, and so this distinction is potentially important.

Interestingly, during the pandemic, those on temporary unemployment and not actively searching return to work at a higher rate than both those actively searching while on temporary layoff as well as those who have been permanently separated. They are also more likely to rejoin their former industry than those actively searching, suggesting that while both groups describe themselves as awaiting recall, the ones not searching are more likely to be recalled. We capture this in our model by allowing for a higher recall rate for the temporary unemployed who are not searching, as compared to the temporary unemployed who are actively searching.

Ultimately, we allow for five labor market states in our model and empirical analysis: employed $(E)$, temporary unemployed and actively searching $\left(T^{A}\right)$, temporary unemployed and not actively searching (or "waiting", $T^{W}$ ), permanent unemployed $(P)$, and not in the labor force $(N)$. The overall unemployment rate combines all unemployed workers $\left(U=T^{A}+T^{W}+P\right)$ and divides by the labor force $(U+E)$. The monthly distribution of the prime-age adult population

\footnotetext{
${ }^{13}$ This has consequences for interpreting transition rates involving those not in the labor force during the COVID-19 recession and should be kept in mind when interpreting the counterfactual scenarios which make assumptions about how quickly these transition rates involving non-participants return to normal.
} 
Table 1

Labor Force Status By Month, 2020

\begin{tabular}{|c|c|c|c|c|c|}
\hline Month & $\begin{array}{c}\text { Employed / } \\
\text { Population } \\
\text { (1) }\end{array}$ & $\begin{array}{l}\text { Temporarily } \\
\text { Unemployed } \\
\text { and Not } \\
\text { Searching / } \\
\text { Population } \\
\text { (2) }\end{array}$ & $\begin{array}{c}\text { Temporarily } \\
\text { Unemployed and } \\
\text { Searching / } \\
\text { Population } \\
\text { (3) }\end{array}$ & $\begin{array}{l}\text { Permanently } \\
\text { Unemployed / } \\
\text { Population } \\
\text { (4) }\end{array}$ & $\begin{array}{c}\text { Out of Labor } \\
\text { Force / } \\
\text { Population } \\
\text { (5) }\end{array}$ \\
\hline January & 0.784 & 0.006 & 0.001 & 0.023 & 0.170 \\
\hline February & 0.782 & 0.006 & 0.001 & 0.022 & 0.171 \\
\hline March & 0.766 & 0.015 & 0.002 & 0.022 & 0.175 \\
\hline April & 0.653 & 0.100 & 0.009 & 0.021 & 0.202 \\
\hline May & 0.681 & 0.076 & 0.011 & 0.022 & 0.196 \\
\hline June & 0.698 & 0.046 & 0.011 & 0.030 & 0.188 \\
\hline July & 0.692 & 0.039 & 0.012 & 0.030 & 0.188 \\
\hline
\end{tabular}

Notes: This table reports share of adults aged 25-55 in each of the 5 labor force states for each month of 2020 using CPS monthly data. See Data Appendix for more details.

across these five groups in 2020 is shown in Table 1. For some of our measurements below, we will combine the two groups of temporary unemployed into a single group $\left(T=T^{A}+T^{W}\right)$.

\section{MEASURING TRANSITION RATES}

We rely on the monthly CPS repeated cross-sections to estimate the distribution across labor force states, and we rely on the matched panel data to estimate transition rates. This section describes how we estimate transition between employment, temporary unemployment, permanent unemployment, and non-participation $(E, T, P, N)$, and we discuss below how we measure transition rates for the two types of temporary unemployed (the actively searching and the "waiting").

Unfortunately, the transition rates directly estimated using the panel are not consistent with the time series of labor forces states obtained from the monthly cross-sections. In particular, denote by $\hat{\Pi}_{t}$ the vector containing the distribution across the four labor force states, as measured in the cross-section in $t$, and denote by $\hat{\Lambda}_{t}$ the four-by-four matrix containing the measured transition rates between each labor market state between time $t$ and $t+1$. If the transition rates $\hat{\Lambda}_{t}$ were consistent with the measured states $\hat{\Pi}_{t}$ each month, then the following 
relationship would hold in the CPS data:

$$
\hat{\Pi}_{t+1}=\hat{\Lambda}_{t} \hat{\Pi}_{t}
$$

As discussed in detail in Kroft et al. (2016), however, it turns out that this identity does not hold in the CPS data, largely because respondents are more likely to report not being in the labor force when interviewed in later months in samples, a phenomenon known as rotation group bias. ${ }^{14}$ Left unaddressed, this bias compounds over time if one simulates a model economy using $\hat{\Lambda}_{t}$; over time, the simulated distributions start to diverge rapidly from those observed in the cross-sectional data.

To address this inconsistency in the data, we assume that the measured distribution $\hat{\Pi}_{t}$ coincides with the true distribution in the population $\Pi_{t}$ each month, and we estimate the transition rates in the population $\left(\hat{\Lambda}_{t}\right)$ in a way that forces consistency with the time series of $\Pi_{t}$. Given the adding-up constraint that the transition rates must add up to 1 for each state, we need to estimate 12 transition rates.

To estimate these transition rates and remain consistent with observed distributions across labor force states, we adapt the approach in Kroft et al. (2016) and Kroft et al. (2019). We sketch this approach here and provide the exact algorithm in the Appendix. ${ }^{15}$

We have a few additional restrictions that we can use when estimating equation 1 , evaluated when replacing $\hat{\Lambda}_{t}$ with $\Lambda_{t}$. First, we normalize the population to be 1 each month (i.e., $E+T+P+N=1$ ), which provides 3 restrictions for identification. Second, the observed fraction of those on permanent or temporary unemployment with duration $(d=0)$ provides us with two additional restrictions on the job loss rates. We thus require $7(=12-5)$ additional restrictions to estimate the transition rates. Let $\lambda_{t}^{X \rightarrow Y}$ denote the transition rate from state $X$ to state $Y$ in period t.

We then estimate the following ratio using estimates of each transition rate:

$$
\frac{\lambda_{t}^{\widehat{X \rightarrow Y} Y}}{\lambda_{t}^{\widehat{X \rightarrow Y} Y}},
$$

and we assume that this ratio of estimated transition rates is a valid estimate of the ratio of

${ }^{14}$ See Krueger et al. (2017) and Ahn and Hamilton (2020) for more detailed discussion.

${ }^{15} \mathrm{Ahn}$ and Hamilton (2020) discuss an alternative approach to address rotation group bias; their approach, however, requires data on all eight of the months in sample for each respondent. Clearly, we do not have the ability to use that approach to estimate transition rates in recent months, so we follow our approach instead so that we can see how transition rates are changing in the first few months of the COVID-19 recession. 
the true transition rates, $\lambda_{t}^{X \rightarrow Y} / \lambda_{t}^{X \rightarrow Y}$. We do this for each of the following seven ratios of transition rates:

$$
\frac{\lambda_{t}^{N \rightarrow P}}{\lambda_{t}^{N \rightarrow E}}, \frac{\lambda_{t}^{E \rightarrow N}}{\lambda_{t}^{E \rightarrow P}}, \frac{\lambda_{t}^{P \rightarrow N}}{\lambda_{t}^{P \rightarrow E}}, \frac{\lambda_{t}^{E \rightarrow R}}{\lambda_{t}^{N \rightarrow R}}, \frac{\lambda_{t}^{P \rightarrow R}}{\lambda_{t}^{N \rightarrow R}}, \frac{\lambda_{t}^{R \rightarrow P}}{\lambda_{t}^{R \rightarrow N}}, \frac{\lambda_{t}^{R \rightarrow E}}{\lambda_{t}^{R \rightarrow N}}
$$

This delivers the final 7 restrictions needed to identify and estimate the 12 unknown transition rates using a system of 12 linear equations. The key assumption is that the biases in the estimated transition rates need to "cancel out" when we take ratios (i.e., that the biases that cause the inconsistency are proportional across each of the pairs of labor market states above). The resulting "adjusted" transition rates are thus estimated to impose consistency in stocks from month to month. We will use these adjusted transition rates throughout our analysis. In the next section, we will present these transition rates as motivating evidence for our model setup and calibration.

\section{II.C. Motivating Figures}

This section presents several figures which show how unique the COVID-19 recession is in terms of changes in stocks and transition rates, especially with respect to temporary unemployment.

We begin with Figure 1 which shows in Panel A how the (seasonally adjusted) monthly unemployment rate evolved since 2000 and focuses in on the last 12 months in Panel B. (All of the figures in this Section will follow this same format.) Between March and April 2020 the unemployment rate spiked by 10 percentage points to just over 15 percent. This is dramatic even in comparison to the increase in unemployment during the Great Recession. It is worth noting that the BLS believes that the initial spike in the unemployment rate would have been even larger if its survey procedures had been followed correctly. By the middle of 2020, the economy clawed back about half of this increase and the unemployment rate stood at just under 10 percent in July 2020.

Figure 2 plots the seasonally-adjusted number of vacancies (in thousands) from JOLTS. Although there is a clear drop in vacancies in March and April 2020, the drop is far less

pronounced (in magnitude) than the rise in unemployment. Notably, even at the depth of the crisis, the number of vacancies is comparable to 2015 - a period typically acknowledged as being a fairly tight labor market. Similar to the unemployment rate, we start to see evidence of a rebound in May 2020 and by July 2020 more than half of the drop has been reversed.

Next, in Figure 3 we show the important role of temporary unemployment during the COVID-19 recession. The figure plots the separation rates for three groups: all employed work- 
Figure 1: Unemployment Rate, 2000-2020

Panel A: Full Sample

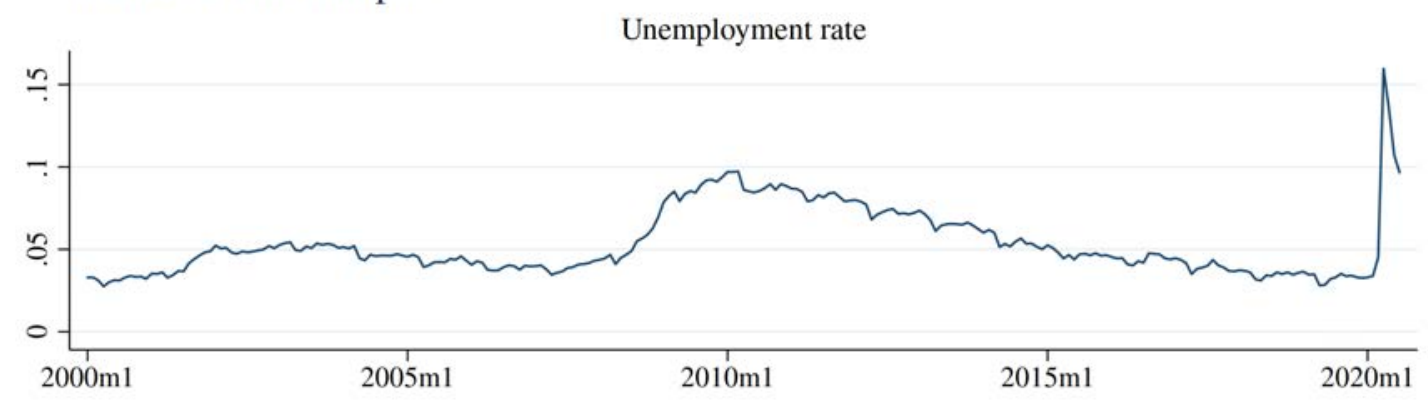

Panel B: July 2019 to July 2020

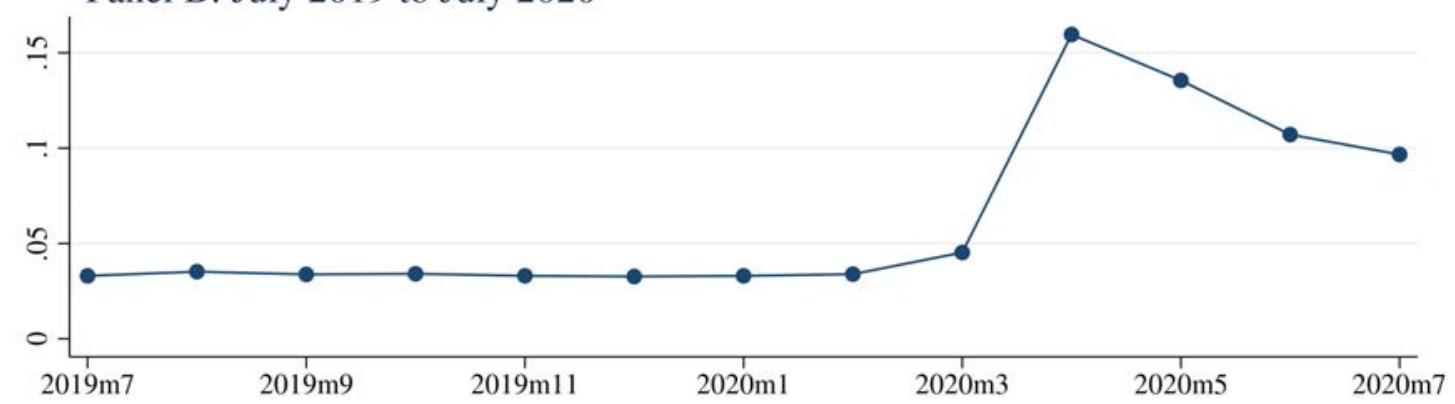

Seasonally adjusted

Notes: This figure reports the unemployment rate using monthly CPS data, and the data is seasonally adjusted by regressing the full time series on month fixed effects that are constrained to be mean zero.

ers flowing into unemployment, only workers flowing into temporary unemployment, and only workers flowing into permanent unemployment. ${ }^{16}$ This figure shows quite clearly what makes the COVID-19 recession unique: the role of temporary layoffs. Unlike separations for workers who have been permanently separated - which shows little change during the initial months of the COVID-19 recession - separation rates into temporary unemployment rose dramatically to roughly 15 percent between March and April 2020, explaining virtually all of the increase in job separations overall. In May, separation rates are around 5 percent, and in June they are down to about 2-3 percent, which is still elevated relative to the pre-2020 average, which is less than 1 percent.

With such a huge inflow of temporary unemployed workers into unemployment, we would of course expect the share of the unemployed that are on temporary layoff to rise drastically,

${ }^{16}$ In the Appendix, we present the separation rates for the temporary unemployed, splitting them into two groups: "regular" temporary layoffs as classified by the BLS and individuals who are "employed but absent for other reasons and unpaid," which we have re-classifed as temporary unemployed in this paper. Here we see that the transition rates for the former group increase quite substantially, while the transition rates for the latter group also increase but to a lesser extent. 
Figure 2: Job Vacancies, 2000-2020
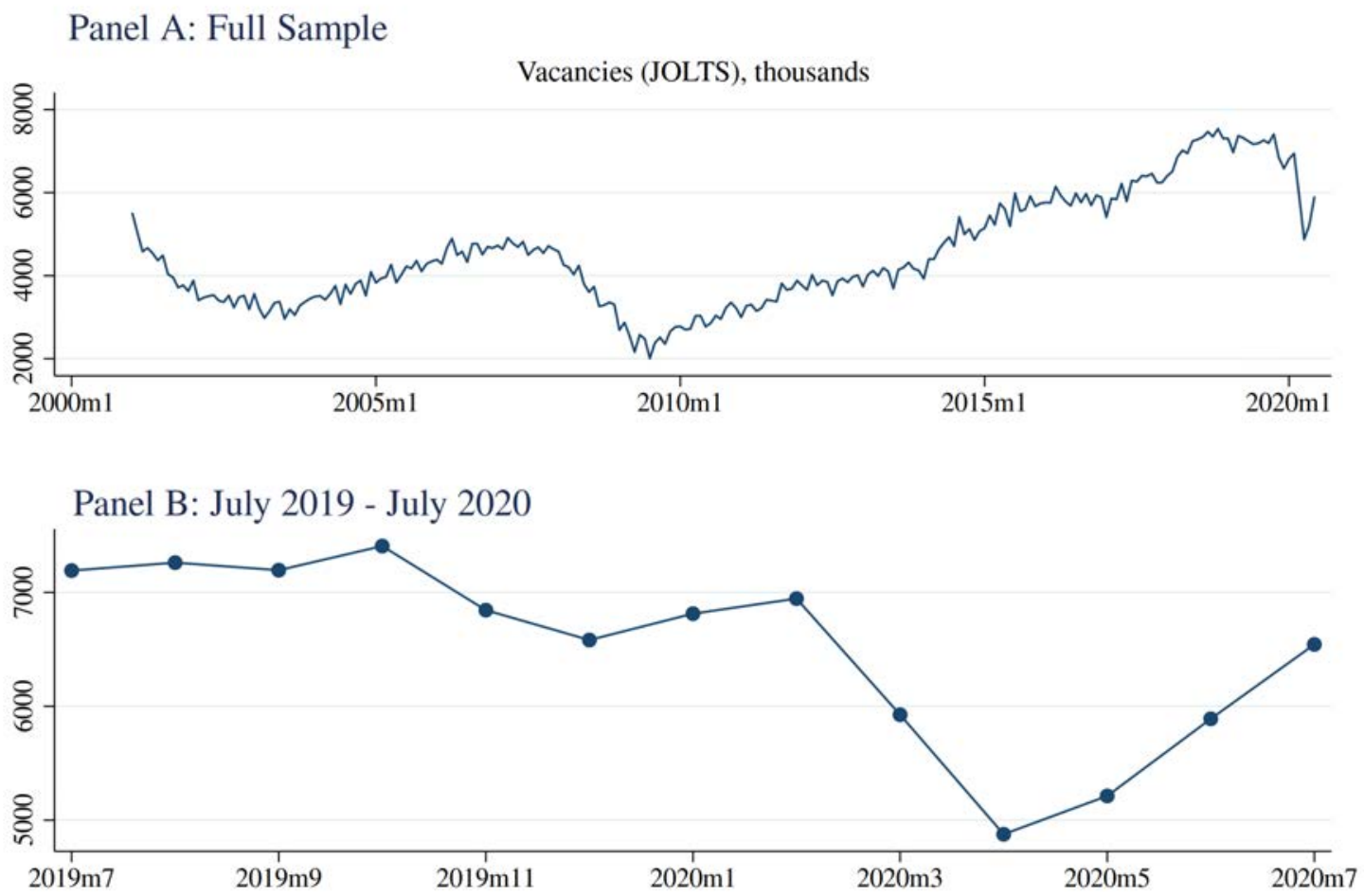

Seasonally adjusted

Notes: This figure reports the JOLTS vacancy series, and the data are seasonally adjusted by regressing the full time series on month fixed effects that are constrained to be mean zero.

and this pattern is shown in Figure 4. In normal economic times (and even during the Great Recession), the share of the unemployed that are on temporary layoff hovers around 20 percent. In April 2020, this share reached 80 percent. By July 2020, the share had fallen to around 60 percent, which is still historically high.

Figure 5 plots the probability of employment in a given month if the worker was unemployed in the prior month (either temporarily or permanently). This is the measure of job finding rates that we use throughout the paper. ${ }^{17}$ Overall, we see that the temporary unemployed have much higher job finding rates compared to the permanent unemployed. This fact combined with the sizeable increase in the number of temporary layoffs in April 2020 explains - at least in an accounting sense - the increase in the overall job finding rate for unemployed workers in May and June 2020. ${ }^{18}$ The elevated job finding rate also explains why the unemployment rate

\footnotetext{
${ }^{17}$ In the Appendix, we show that the "regular" temporary unemployed workers and the "employed but absent from work for other reasons and unpaid" have very similar job finding rates. This suggests that classifying the latter group as temporarily unemployed is appropriate during the last few months. This approach of classifying workers based on their job finding rates follows Jones and Riddell (1999).

${ }^{18}$ Note there is a one-month lag since they enter into unemployment in April and thus the job finding rate for these individuals is based on employment status in May and June.
} 
Figure 3: Separation Rates, 2000-2020

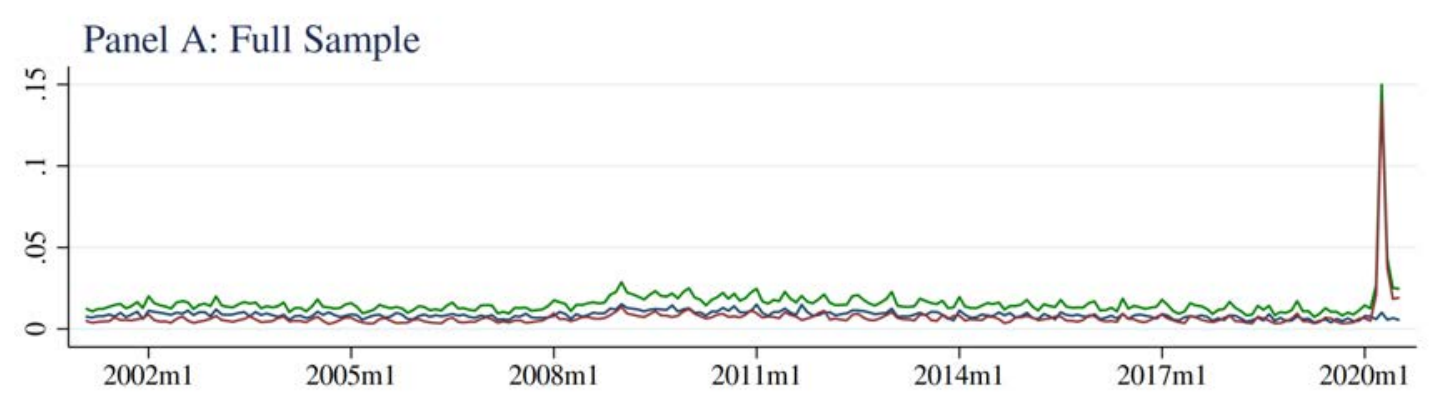

Panel B: July 2019 to July 2020

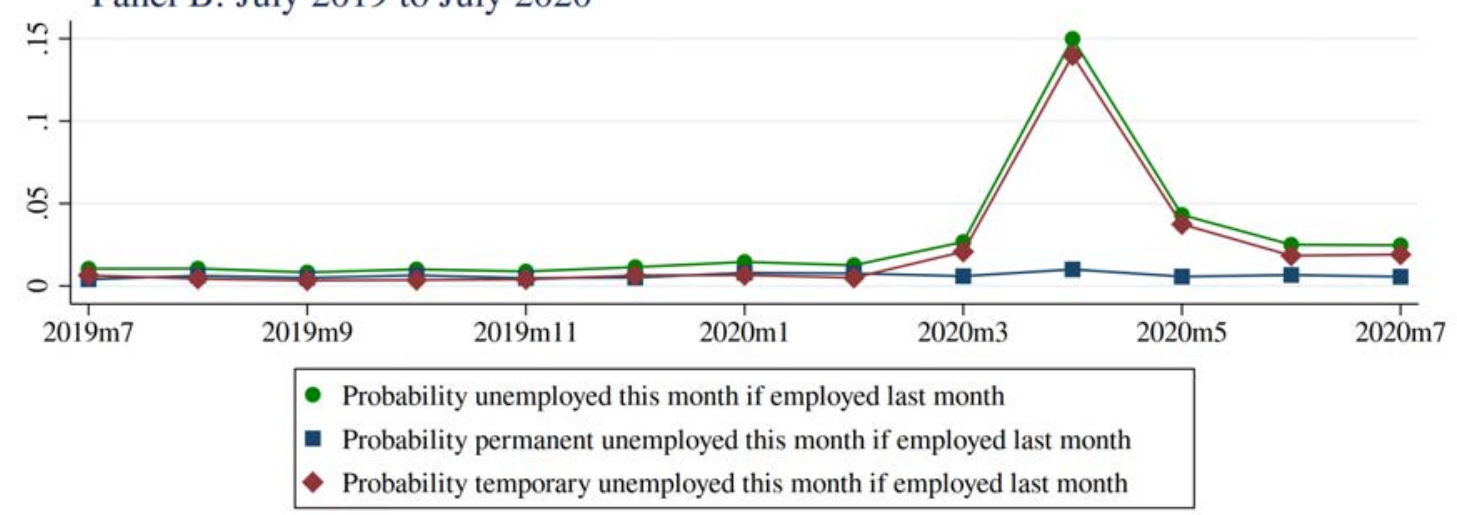

Notes: This figure reports the transition rate from employment to temporary unemployment using the adjusted transition rates measuring using the monthly CPS data. Each month reports the transition rate from the employed population in the previous month (i.e., it is a $t-1$ to $t$ transition rate). The transition rates are shown into temporary and permanent unemployment. The definition of temporary unemployment includes both individuals who report being on temporary layoff as well as those who report being employed and "absent from work for other reasons" and unpaid. This group is defined as temporary unemployed in all of the main analysis. See main text and Data Appendix for more details.

dropped by about 5 percentage points in May and June as many unemployed individuals were recalled to their former jobs.

Looking at job finding rates within each type of worker, we do not see much evidence of a change for a large decline in the job finding rate for either temporarily or permanently unemployed individuals during the COVID-19 recession. The experience during the Great Recession was quite different, highlighting the uniqueness of the COVID-19 shock. During the Great Recession, a decline in the outflows from unemployment played a large role in leading the labor market into the downturn. The COVID-19 downturn by contrast is characterized by a rapid, unprecedented increase in the inflows into temporary unemployment, with relatively muted overall changes in the outflow rate conditional on type of unemployment. What has led to a change in job finding rates is the compositional shift towards temporary unemployment 
Figure 4: Share of Unemployed on Temporary Layoff

Panel A: Full Sample

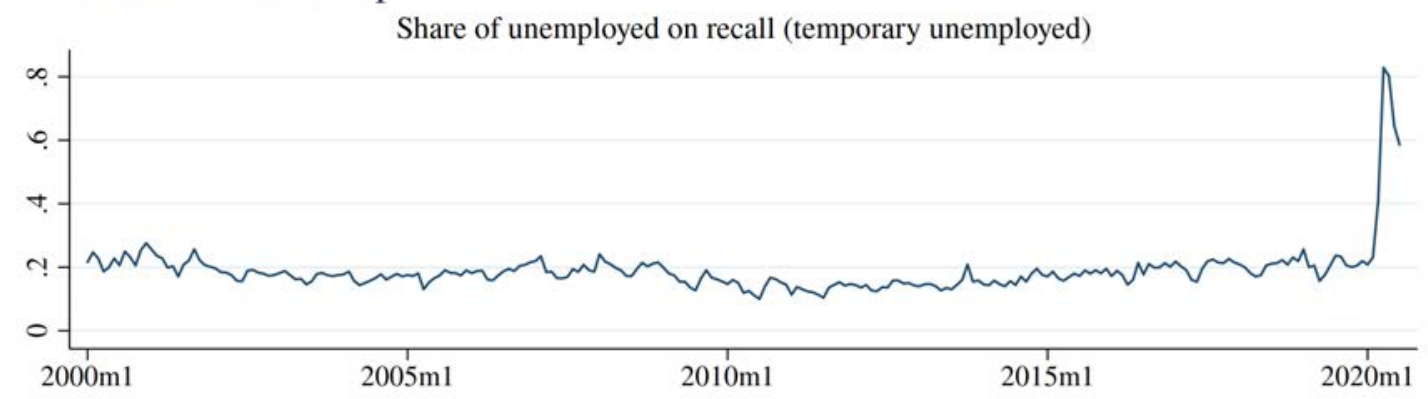

Panel B: July 2019 to July 2020

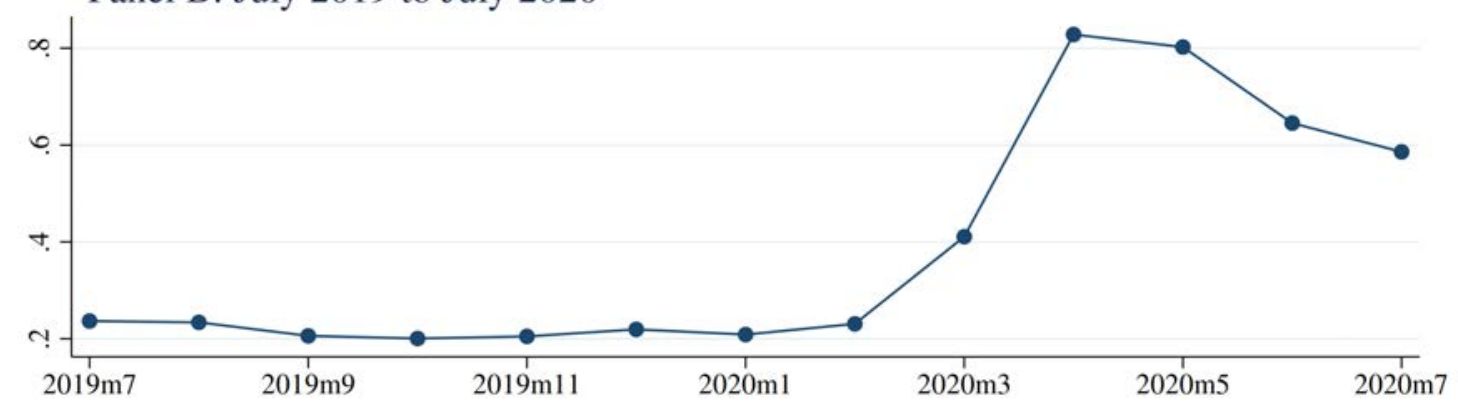

Seasonally adjusted

Notes: This figure reports the seasonally-adjusted share of the unemployed on temporary layoff using monthly CPS data. See Figure 1 notes for more details on seasonal adjustment.

which increased outflows from unemployment over the pandemic period.

An important concern about temporary layoffs is that they can become permanent layoffs as the COVID-19 recession worsens, as emphasized in Katz (1986) and Katz and Meyer (1990). Figure 6 plots the average probability that a worker becomes permanently displaced if they are on recall in the prior month, as well as the probability that a worker becomes temporarily unemployed next month if they have been permanently unemployed. Figure 6 shows that the chance of transitioning from $P$ to $T$ is much smaller than the probability of a transition in the opposite direction. In recent months, however, there has been an extremely sharp rise in the $\lambda_{t}^{P \rightarrow T}$ transition rate. Although we do not know exactly what explains this rise, we speculate that it is due to the fluid boundary between the different states of non-employment during the pandemic period. Consistent with this interpretation, we observe a similar pattern for transitions between non-participation and temporary unemployment in recent months.

Overall, we see in Figure 6 that the rate of transitioning from temporary to permanent unemployment hovers around 10 percent during normal times and is slightly lower during the 
Figure 5: Job-Finding Rates for the Temporary and Permanent Unemployed

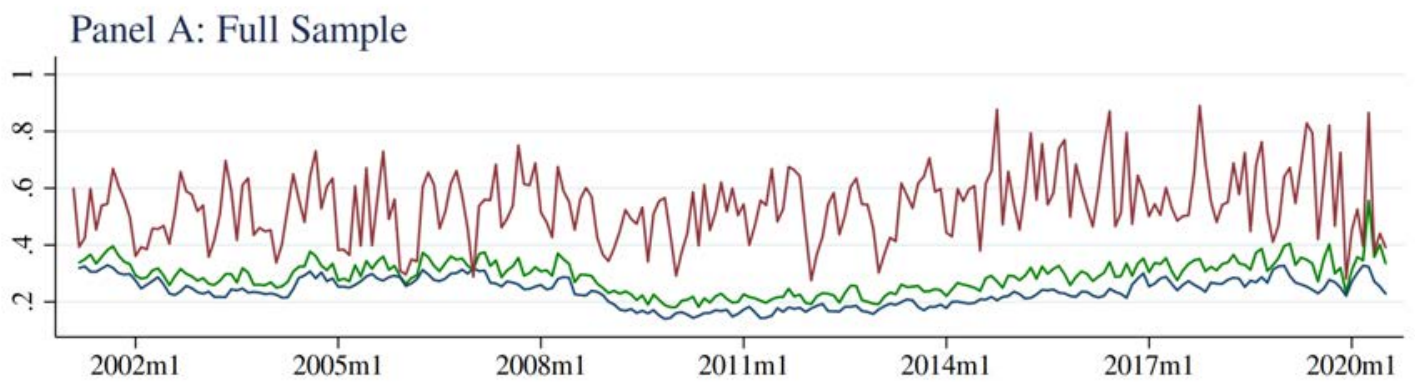

Panel B: July 2019 to July 2020

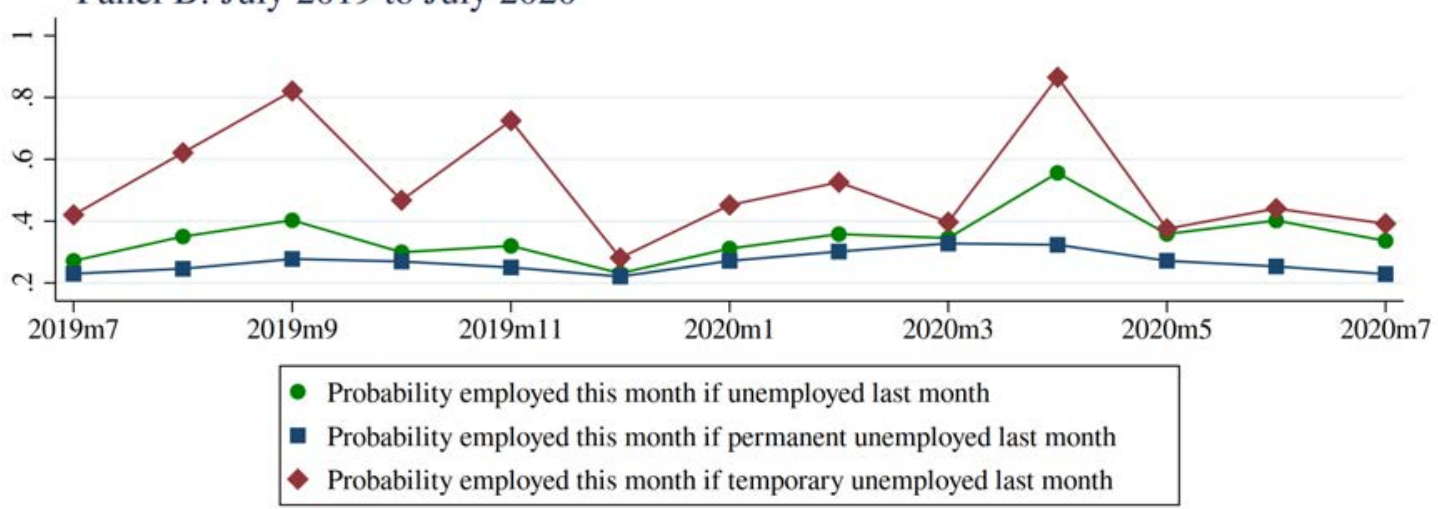

Notes: This figure reports the transition rate from employment to temporary unemployment using the adjusted transition rates measuring using the monthly CPS data. Transitions into employment require the individual to report being employed for two consecutive months (i.e., they are UEE transitions in the CPS).

initial months of the COVID-19 recession with a recent uptick in July. ${ }^{19}$ Given the huge inflow of temporarily unemployed workers in April 2020, this implies that the stock of workers who are permanently unemployed may eventually begin to rise in the future, which we will assess below using predictions from our calibrated model. But even according to the most recent data, some workers who were initially expecting to be recalled when their unemployment spell began have been permanently laid off, transitioning from temporary to permanent unemployment.

At this point, we are only capturing the first few months after layoff for many workers who are currently unemployed. It could be the case that as the COVID-19 recession continues, more workers will transition into permanent unemployment. To investigate this possibility more closely, Figure 7 plots the probability that a worker transitions from temporary to permanent as a function of the duration of their elapsed unemployment spell. This figure shows that the

${ }^{19}$ Note that there are relatively few workers in temporary unemployment in any given month prior to the COVID-19 recession. As a result, the monthly transition rates are very noisy pre-2020. On the other hand, rates are much smoother in recent months when there are many more temporary unemployed workers. 
Figure 6: Transition Rates Between Temporary and Permanent Unemployment
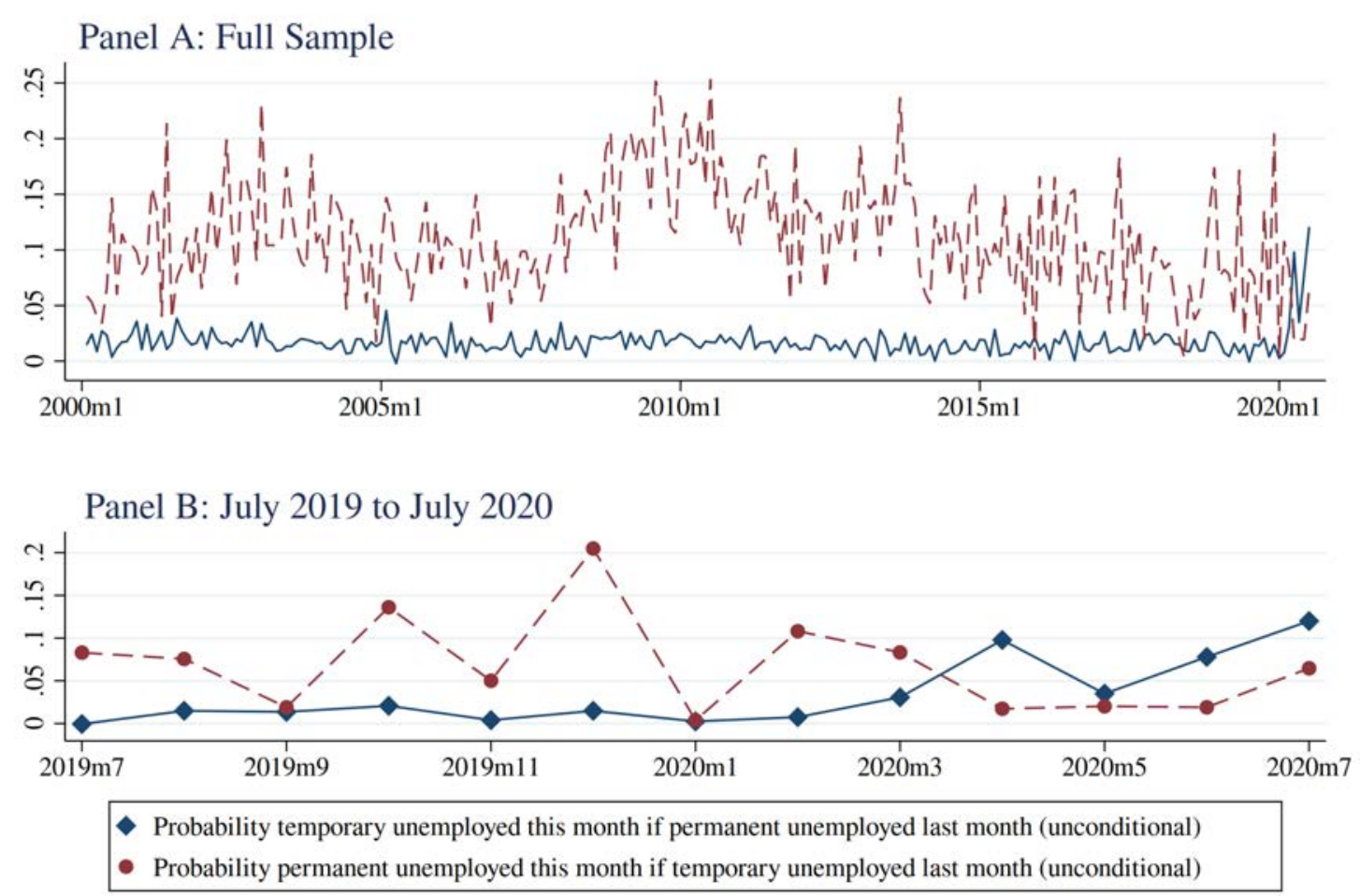

Seasonally adjusted

Notes: This figure reports the seasonally-adjusted transition rates between temporary and permanent unemployment using the matched panel CPS monthly data covering the period 2000-2020. See Figure 1 notes for more details on seasonal adjustment. The temporary unemployed includes individuals waiting to be recalled as well as those actively searching and also includes individuals who report being employed but were unpaid and absent from work for other reasons.

hazard rate is increasing with duration, starting from around 10 percent in the initial month of unemployment and reaching 15-20 percent about 6-8 months later. This evidence suggests that as the COVID-19 recession continues, we may expect to see more workers moving into permanent unemployment, and our model captures this particular kind of "duration dependence," where the longer a temporary unemployed individual is unemployed, the more likely they are to transition into permanent unemployment. 
Figure 7: Transitions Between Permanent and Temporary Unemployment by Unemployment Duration
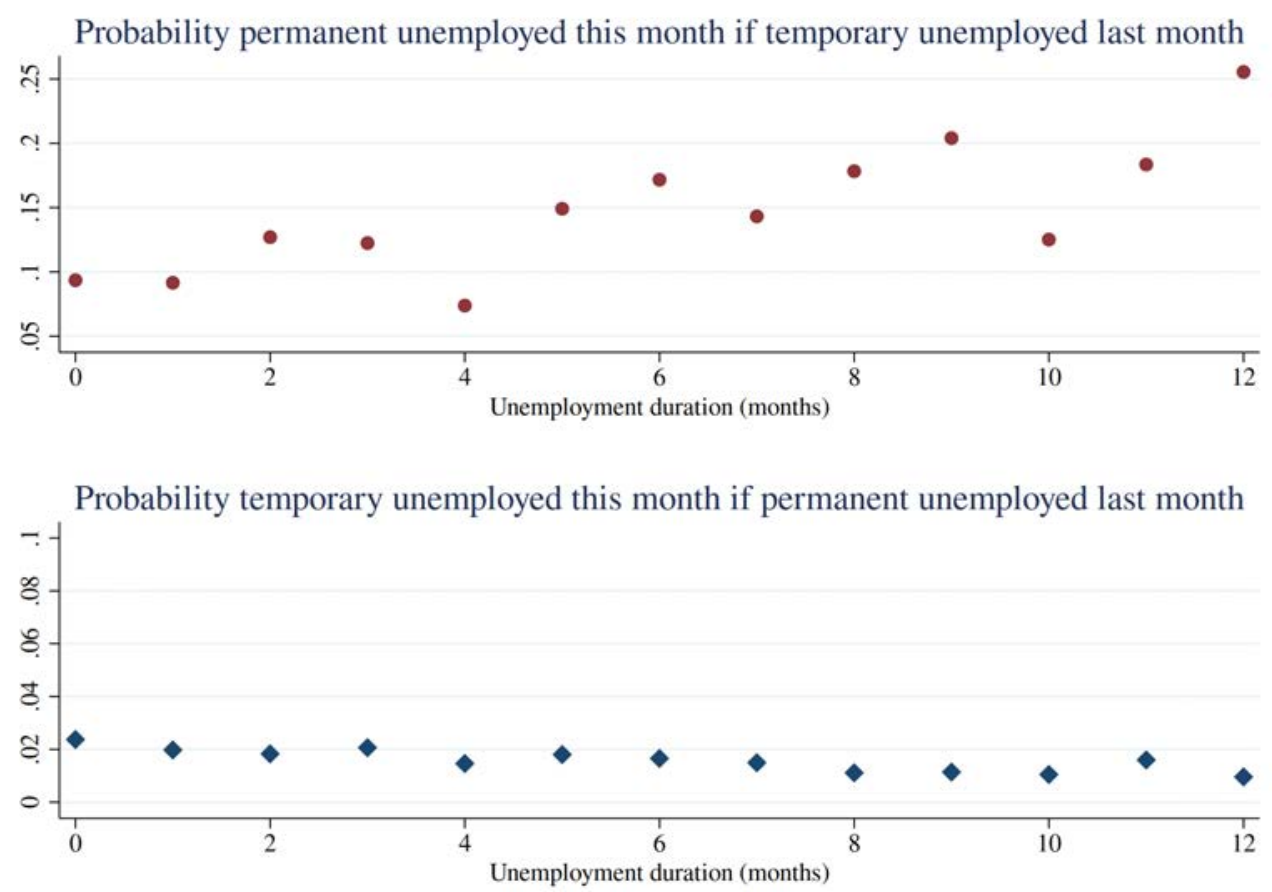

Notes: This figure reports the transition rates between temporary and permanent unemployment by unemployment duration using the matched panel CPS monthly data covering the period 2000-2020.

\section{Search-and-Matching Model with Temporary Un- employment}

The previous section described trends in unemployment and vacancies, and highlighted the importance of temporary unemployment in recent months. Using these figures as motivation, this section goes through a search-and-matching model with temporary unemployment that builds on and extends our model in Kroft et al. (2016). We begin with the basic setup, and then we discuss the "forcing variables" that we treat as exogenous in the model. We then describe the (endogenous) job finding rates that are determined by the matching model. Lastly, we describe our approach to estimation and calibration, report our estimated model parameters, and assess the fit of the model in recent months.

\section{III.A. Model setup}

We allow for four labor force states that display persistence. The persistent states are $(E, T, P, N)$. The states $E$ and $N$ refer to employment and non-participation (not in the labor force); perma- 
nent unemployment $(P)$ refers to unemployed workers who have been permanently laid off and are actively searching, and $T$ refers to unemployed workers who are on temporary layoff. For all unemployed workers $(P$ and $T)$, we will be able to measure the ongoing duration of their unemployment spell, which we index by $d$.

In addition to these four primary labor force states, we also introduce a transitory distinction for the temporary unemployed between those who are "actively searching for work" $\left(T^{A}\right)$ and those "waiting to be recalled" $\left(T^{W}\right)$, so that $T=T^{A}+T^{W}$. In our model, we assume that the states $\left(T^{A}, T^{W}\right)$ are transitory in that we assume that at the beginning of a period, individuals who are temporarily unemployed are randomly assigned to either $T^{A}$ or $T^{W}$ with probability $q_{t}=\operatorname{Pr}\left(T^{A} \mid T\right)$. Conditional on being in labor force state $T$, this probability is independent of all other past variables, and it is directly estimated from the data as the share of those in temporary unemployment who respond that they are actively searching for work. As this share $q_{t}$ changes over time, we will capture variation in how many individuals on temporary unemployment contribute to congestion in the matching process.

The transitory identity of the temporary unemployed $\left(T^{A}\right.$ or $\left.T^{W}\right)$ only affects job finding rates, and we describe how we model these job finding rates in section III.C. below. Both types of temporary unemployed individuals have the same transition rates to $(N, P)$ and from $(E, P, N)$. One key advantage of this setup is that we can estimate transition rates from the larger group of all temporary unemployed workers prior to the COVID-19 recession, which allows for more precise and stable estimates. More importantly, by making the two temporary unemployment states transitory, we ensure that we do not have to account for the unemployment duration dynamics in each state separately. This modelling compromise is primarily motivated by the relatively small number of temporary unemployed workers in the pre-2020 period, and by our desire to calibrate the model entirely on pre-2020 data. ${ }^{20}$ Empirically, we do observe some persistence in these states, but our approach can still capture the congestion effect from increased search as temporary unemployed move from "waiting" to "searching."

Given this setup, we need to keep track of transition rates between the four primary states $(E, T(d), P(d), N)$, and we index the unemployment states by $d$ to emphasize that that transition rates may vary by duration. We use the notation $\lambda_{t}^{X \rightarrow Y}$ to indicate that transition rate from state $X$ to state $Y$ in time $t{ }^{21}$ For those on temporary unemployment, we separately model

\footnotetext{
${ }^{20}$ If we instead had allowed for persistence in $A$ and $W$, then we would need to also account for the different duration structure within these groups and would have to model transition rates conditional on these durations separately.

${ }^{21}$ Note that our notation allows for non-zero transitions between $\left(d, d^{\prime}\right)$ even when $d^{\prime} \neq d+1$, which, as discussed above, does occur fairly frequently in the CPS panel, where we observe that transitions occur across the entire duration distribution. This needs to be accounted for, otherwise the dynamics of the duration
} 
the job finding rates $\lambda_{t}^{T^{W}(d) \rightarrow E}$ and $\lambda_{t}^{T^{A}(d) \rightarrow E}$ for those waiting and those actively searching.

\section{III.B. Forcing Variables}

Our forcing variables are the vacancy rate as well as all of the transitions rates that do not involve flows into employment, plus the job finding rate for $T^{W}$. For each of these variables, we measure the rates from the data directly. When we explore counterfactual simulations, we assume different time paths for these forcing variables and then explore the implications for the job finding rates of different types of workers and the endogenous distributions of labor market states. Given this setup, the forcing variables are the following:

1. Job separation rates $\lambda_{t}^{E \rightarrow Y}$ for $Y \in(T(d), P(d), N)$. Note that not all transitions from employment $E$ go to $d=0$, as discussed above.

2. Transition rates between the different non-employment categories: $\lambda_{t}^{X \rightarrow Y}$, for $X \in(T(d), P(d), N)$ and $Y \in(T(d), P(d), N)$.

3. The job finding rate of those on temporary unemployment who are not actively searching (and thus waiting to be recalled), $\lambda_{t}^{T^{W} \rightarrow E}$. Unlike the permanent unemployed and the temporary unemployed who are actively searching, we do not allow for duration dependence in the job finding rates for this group (i.e., the job finding rate is allowed to vary over time, but does not vary with $d$ ). This assumption is broadly supported by the evidence in Appendix Figure A1 which shows a clearer pattern of negative duration dependence for the temporary unemployed who are actively searching, compared to the temporary unemployed who are not actively searching. In our model, duration dependence for the temporary unemployed who are not actively searching comes through their potential transition to actively searching as temporary unemployed or by transition to permanent layoff (since in both of those cases, the individual then begins to experience negative duration dependence).

The transition rates involving the temporary unemployed (other than the job finding rates) are assumed to be the same for those waiting and for those actively searching; i.e., $\lambda_{t}^{E \rightarrow T^{W}(d)}$ is assumed to be equal to $\lambda_{t}^{E \rightarrow T^{A}(d)}$ (and equal to $\lambda_{t}^{E \rightarrow T(d)}$ ).

structure evolve erratically in the counterfactual simulations. As in Kroft et al. (2016), we estimate the empirical distributions of unemployment durations that individuals transition into and we use these distributions in our counterfactual scenarios for transitions $\lambda_{t}^{X \rightarrow Y(d))}$ where $X \in\{E, N\}$ and $Y \in\{T, P\}$, and we also estimate $\lambda_{t}^{T(d) \rightarrow P(d)}$ and $\lambda_{t}^{P(d) \rightarrow T(d)}$ empirically, as well. This estimation approach is described in more detail in the Appendix. 


\section{III.C. Job Finding Rates}

The main endogenous objects of the search-and-matching model are the job finding rates, which are determined by market tightness - defined as the ratio between vacancies and aggregate search across all non-employed individuals. We define the time-varying aggregate search $\left(S_{t}\right)$ to include the search effort by $N, P(d)$, and $T(d)$ workers. The units of this variable are defined to be the equivalent search effort of $S_{t}$ permanent unemployed individuals with duration $d=0$.

The total number of matches in time $t$ is determined by the following $M\left(S_{t}, V_{t}\right)$ function:

$$
M\left(S_{t}, V_{t}\right)=m_{0}\left(S_{t}^{\alpha} V_{t}^{(1-\alpha)}\right)
$$

The match rate per unit of search effort is given by $\frac{M\left(S_{t}, V_{t}\right)}{S_{t}}=m_{0} x_{t}^{1-\alpha}$, where $x_{t}=\frac{V_{t}}{S_{t}}$ is market tightness (the ratio of vacancies to total search effort).

\section{JOB FINDING RATES FOR THE PERMANENT UNEMPLOYED AND THOSE NOT IN THE LABOR FORCE}

The job finding rate at time $t$ for the permanent unemployed with duration $d$ is given by the following:

$$
\lambda_{t}^{P(d) \rightarrow E}=\operatorname{Prob}\left(E_{t} \mid P_{t-1}(d)\right)=A(d) m_{0} x_{t}^{1-\alpha}
$$

where $A(d)$ is a declining, always-positive function with $A(d=0)=1$. This function captures the duration dependence in job finding rates as in Kroft et al. (2016) and Krueger et al. (2014), and it is assumed to be fixed over time and estimated using the relative job finding rates among the unemployed of different joblessness durations.

Those out of the labor force $(N)$ are assumed to search with intensity $s \in[0,1]$, which is estimated within the model and (like $A(d)$ function) is assumed to be fixed over time. The job finding rate is given by:

$$
\lambda_{t}^{N \rightarrow E}=\operatorname{Prob}\left(E_{t} \mid N_{t-1}\right)=s m_{0} x_{t}^{1-\alpha}
$$

These expressions are similar to Kroft et al. (2016), except that total search $S_{t}$ is not specified yet. To specify $S_{t}$, we need to model the job finding rates of the temporary unemployed.

\section{JOB FINDING RATES FOR THE TEMPORARY UNEMPLOYED}

Among the temporary unemployed, we distinguish between those actively searching for a job and those waiting for a recall. As described above, we assume that the distinction between the 
temporary unemployed engaged in waiting $\left(T^{W}(d)\right)$ and the temporary unemployed actively engaged in search $\left(T^{A}(d)\right)$ is transitory.

We define the share of temporary unemployed individuals who are actively searching by $q_{t}$ so that $T_{t}^{A}(d) \equiv q_{t} T_{t}(d)$ and $T_{t}^{W}(d) \equiv\left(1-q_{t}\right) T_{t}(d)$. The CPS asks those on temporary unemployment whether or not they are actively searching for employment and we can thus measure $q_{t}$ directly at each point in time. ${ }^{22}$

In our model, the waiting temporary unemployed $\left(T^{W}(d)\right)$ do not congest the labor market, and their job finding rate is given by the exogenous forcing variable $\lambda_{t}^{T^{W}} \rightarrow E$. Those actively searching for a job while on temporary layoff, on the other hand, are congesting the labor market, and their job finding rates are partially endogenous. In particular, we assume that each period the temporary workers are actively searching are either recalled or hired by a new employer as a result of their active search.

We assume that those actively searching for work among the temporary unemployed are less likely to be recalled to their former employer, so that the recall rate for $T_{t}^{A}(d)$ is $\pi \lambda_{t}^{T^{W} \rightarrow E}$, where $0<\pi<1$. The parameter $\pi$ captures the notion that this group of individuals is actively searching precisely because they understand that they are less likely to be recalled this period. Note that $\pi$ does not vary over time or with duration. We calibrate this parameter using data from the pre-2020 period and we focus on variation in $q_{t}$ in recent months since we can directly measure this in the data.

Conditional on not being recalled, the temporary unemployed actively searching find jobs at the same rate as the permanently unemployed $P_{t}(d)$, and they congest the labor market similarly. This assumption is supported by Figure 8 below, which shows (proportionally) similar negative duration dependence among the actively searching temporary unemployed and the permanent unemployed. In both cases, the job finding rate is negatively related to unemployment duration.

Given this setup, the job finding rate of $T^{A}$ is thus given by

$$
\lambda_{t}^{T^{A}(d) \rightarrow E}=\pi \lambda_{t}^{T^{W} \rightarrow E}+\left(1-\pi \lambda_{t}^{T^{W} \rightarrow E}\right) \lambda_{t}^{P(d) \rightarrow E} .
$$

From equation (5), we can estimate $\pi$ by calculating the value of $\pi$ implied by the equation each month using the observed job finding rates, and then taking the average of this value

\footnotetext{
${ }^{22}$ For parsimony, we do not allow $q_{t}$ to vary with duration $d$ because we do not believe we have enough data in the pre-2020 sample period to estimate that reliably. We are interested in how $q_{t}$ varies over time, however especially in recent months - since as $q_{t}$ changes, the share of temporary unemployed who are actively searching and thus congesting the matching process is changing.
} 
Figure 8: Duration Dependence in Permanent and Temporary Unemployment

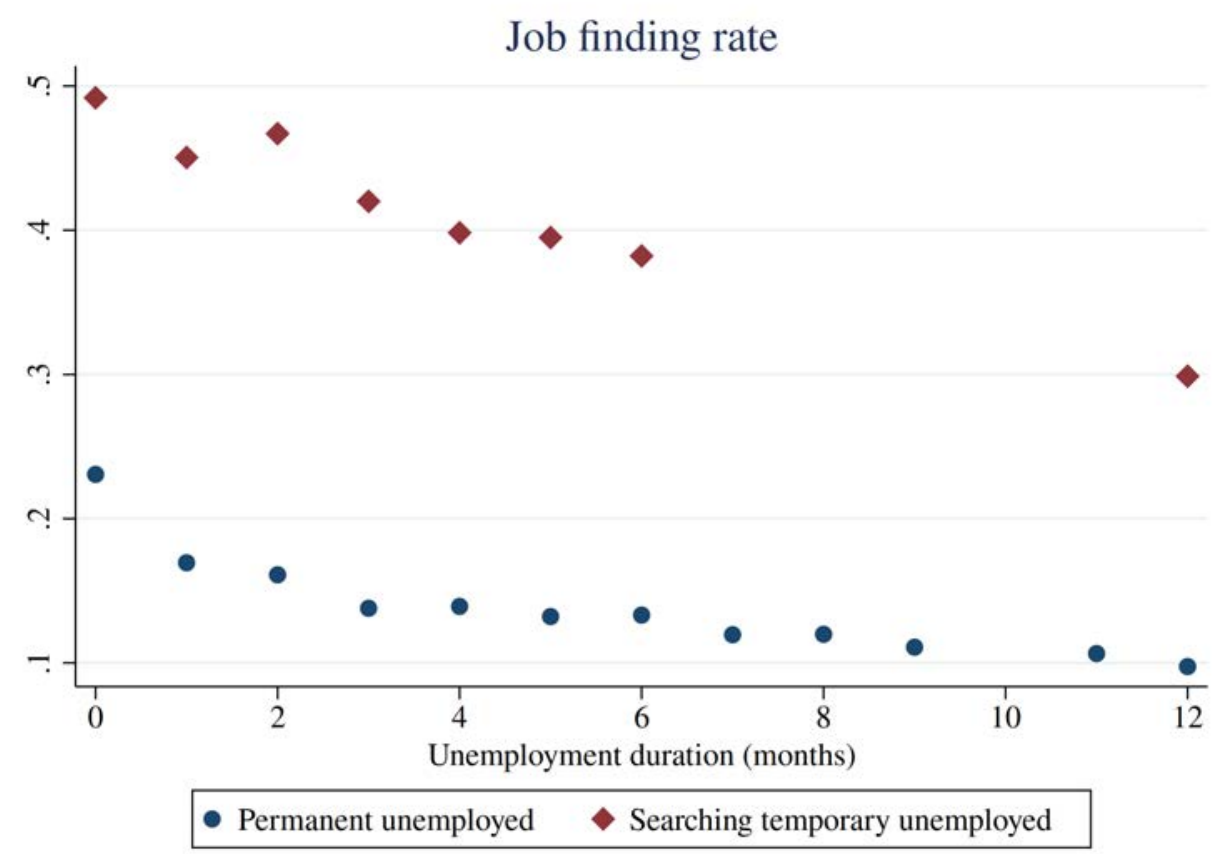

Notes: This figure is calculated using the CPS matched panel data and reports the average monthly job finding rate by unemployment duration, pooling data from the 2000-2019 sample period. The figure compares how job finding rate varies with unemployment duration for the permanent unemployed and the temporary unemployed (restricted to those who are actively searching for work). The proportional decline in the job finding rate is similar across the two groups, implying similar duration dependence for both groups of unemployed individuals. We omit months where there are fewer than 150 observations in the data. 
across months as our estimate of $\pi$. This leads to the following estimate for $\pi$ :

$$
\hat{\pi}=\frac{1}{T} \sum \frac{\tilde{\lambda}_{t}^{T^{A} \rightarrow E}-\tilde{\lambda}_{t}^{P \rightarrow E}}{\tilde{\lambda}_{t}^{T^{W} \rightarrow E}\left(1-\tilde{\lambda}_{t}^{P \rightarrow E}\right)}
$$

The $\tilde{\lambda}$ notation indicates that we calculate each transition rate using a common duration distribution, which we implement by re-weighting each of the transition rates to have the same duration distribution. We feel this approach is more robust because of the rapidly changing duration structure of temporary unemployment in 2020, and we calculate our estimate of $\pi$ using this approach since in principle $\pi$ could also vary by unemployment duration, as well.

\section{LABOR MARKET TIGHTNESS}

Given the matching model above, there are three groups that contribute to labor market tightness: $P, T^{A}$, and $N$, where the first two are composed of individuals with different distributions of unemployment durations.

As in Krueger et al. (2014), unemployed individuals with different durations contribute to overall search in proportion to their job finding rates. Define $\bar{P}_{t}$ as the following weightedaverage of the permanent unemployed in time $t$ :

$$
\bar{P}_{t}=\sum_{d=1}^{D} A(d) P_{t}(d)
$$

The expression for $\bar{P}_{t}$ accounts for the effects of changes in the unemployment duration distribution on total search effort. Intuitively, if the permanent unemployed is mostly long-term unemployed, then they have lower job finding rates and contribute less to labor market tightness. ${ }^{23}$

In our model, we extend this logic to the temporary unemployed. Since we assume the temporary unemployed are actively searching for jobs at the same rate as the permanent unemployed (conditional on duration and conditional on not being recalled), then we can define an analogous weighted-average for the active temporary unemployed as follows:

$$
\overline{T_{t}^{A}}=\sum_{d=1}^{D} A(d) T_{t}^{A}(d)
$$

\footnotetext{
${ }^{23}$ As described by Krueger et al. (2014), this is one sense in which the long-term unemployed were "on the margins" of the labor market during the Great Recession.
} 
Now we are ready to obtain our expression for total search $S_{t}$ :

$$
S_{t}=\bar{P}_{t}+\left(1-\pi \lambda_{t}^{T^{W} \rightarrow E}\right) \overline{T_{t}^{A}}+s N_{t}
$$

Together with (2) and vacancies $V_{t}$, we can calculate time-varying market tightness and can calculate the matching rates needed to determine the endogenous job finding rates. The new term in equation (7) relative to Kroft et al. (2016) and Krueger et al. (2014) is the contribution of temporary unemployed to market tightness, which is scaled by the probability they are not recalled and end up actively searching for work.

\section{III.D. Estimation and Calibration of Model Parameters}

We calibrate the model in the following steps, which broadly follow the procedure outlined in Kroft et al. (2016), adapted to our model that allows for temporary unemployment. We briefly summarize the approach here and refer the reader to Kroft et al. (2016) for more details.

1. We use CPS monthly data to estimate stocks and transition rates of the labor market states, as described in the Data section above, and assign flows from non-participation into unemployment using the pre-2020 average distribution of unemployment durations that non-participants transition into. The Appendix provides more details on how we process the CPS data.

2. We estimate the $A(d)$ function that characterizes how the job finding rate varies with unemployment duration using the same functional form as Kroft et al. (2016), $A(d)=$ $\left(1-a_{1}-a_{2}\right)+a_{1} \exp \left(-b_{1} \times d\right)+a_{2} \exp \left(-b_{2} \times d\right)$. We pool the pre-2020 data on job finding rates for the unemployed and report the Nonlinear Least Squares estimates in Table 2. We estimate the $A(d)$ function pooling together the temporary unemployed who are actively searching and the permanent unemployed, since Figure 8 suggests that the job finding rate declines proportionally for both groups. ${ }^{24}$ For comparison, Table 2 reports the parameter estimates from Kroft et al. (2016), which are very similar to the $A(d)$ estimates based on the full 2001-2019 sample period. This suggests a fairly stable relationship between unemployment duration and the job finding rate.

3. Lastly, we estimate the remaining model parameters by minimum distance, minimizing the distance between the observed job finding rates of the unemployed and the model-implied

${ }^{24}$ When we estimate $A(d)$ separately for $T^{A}(d)$ and $P(d)$ we find similar parameter estimates, so we opted for a single $A(d)$ function for both groups for simplicity. 
job finding rates over the entire pre-2020 sample period. We report these estimates in Table 2, as well. We find fairly similar matching model parameter estimates for the full 2001-2019 period as we found in Kroft et al. (2016) using only pre-2008 data, but with a slightly lower search intensity of non-participants.

Table 2

Model parameter estimates

\begin{tabular}{|c|c|c|c|}
\hline Model: & $\begin{array}{l}\text { 2000-2019 data, } \\
\text { full model with } \\
\text { temporary } \\
\text { unemployment } \\
\text { (1) }\end{array}$ & $\begin{array}{c}\text { 2000-2019 data, } \\
\text { no temporary } \\
\text { unemployment } \\
(2)\end{array}$ & $\begin{array}{c}\text { KLNK (2016) } \\
\text { estimates, pre- } \\
2008 \text { data, } \\
\text { no temporary } \\
\text { unemployment } \\
\text { (3) }\end{array}$ \\
\hline \multicolumn{4}{|c|}{ Duration dependence parameters } \\
\hline$a_{1}$ (intercept parameter 1$)$ & 0.273 & 0.275 & 0.314 \\
\hline$a_{2}$ (intercept parameter 2 ) & 0.426 & 0.431 & 0.393 \\
\hline$b_{1}($ slope parameter 1$)$ & 1.658 & 1.027 & 1.085 \\
\hline$b_{2}($ slope parameter 2$)$ & 0.065 & 0.099 & 0.055 \\
\hline
\end{tabular}

\section{Temporary unemployment parameter}

$\pi$ (recall rate of "actively searching" relative to

"waiting" temporary unemployed)

0.321

\section{Matching model parameters}

$\alpha$ (exponent in matching function)

0.717

0.729

0.753

$m_{0}$ (scale parameter)

0.422

0.495

0.435

$s$ (relative search intensity of non-participants)

0.265

0.220

0.218

Notes: This paper reports parameter values from each step of the model calibration. The first set of estimates are the duration dependence parameters, which are estimated using non-linear least squares and the job finding rates from the matched monthly CPS data. The second set of estimates are the parameters for temporary unemployed, which are directly measured using the CPS data, and are based on averages taken over the entire 2002-2019 sample period. The final set of estimates are the matching model parameters, which are estimated by minimizng the distance between the observed job finding rates and the job finding rates predicted by the model during the 2002-2019 period. Column (1) reports estimates for the baseline model in this paper that distinguishes betwen temporary and permanent unemployment, while columns (2) and (3) report estimates for the model in Kroft et al. (2016) that does not model temporary unemployment and estimates are based on 2002-2019 and 2002-2007 data, respectively. 
Figure 10: Assessing the In-Sample and Out-of-Sample Fit of the Baseline Model
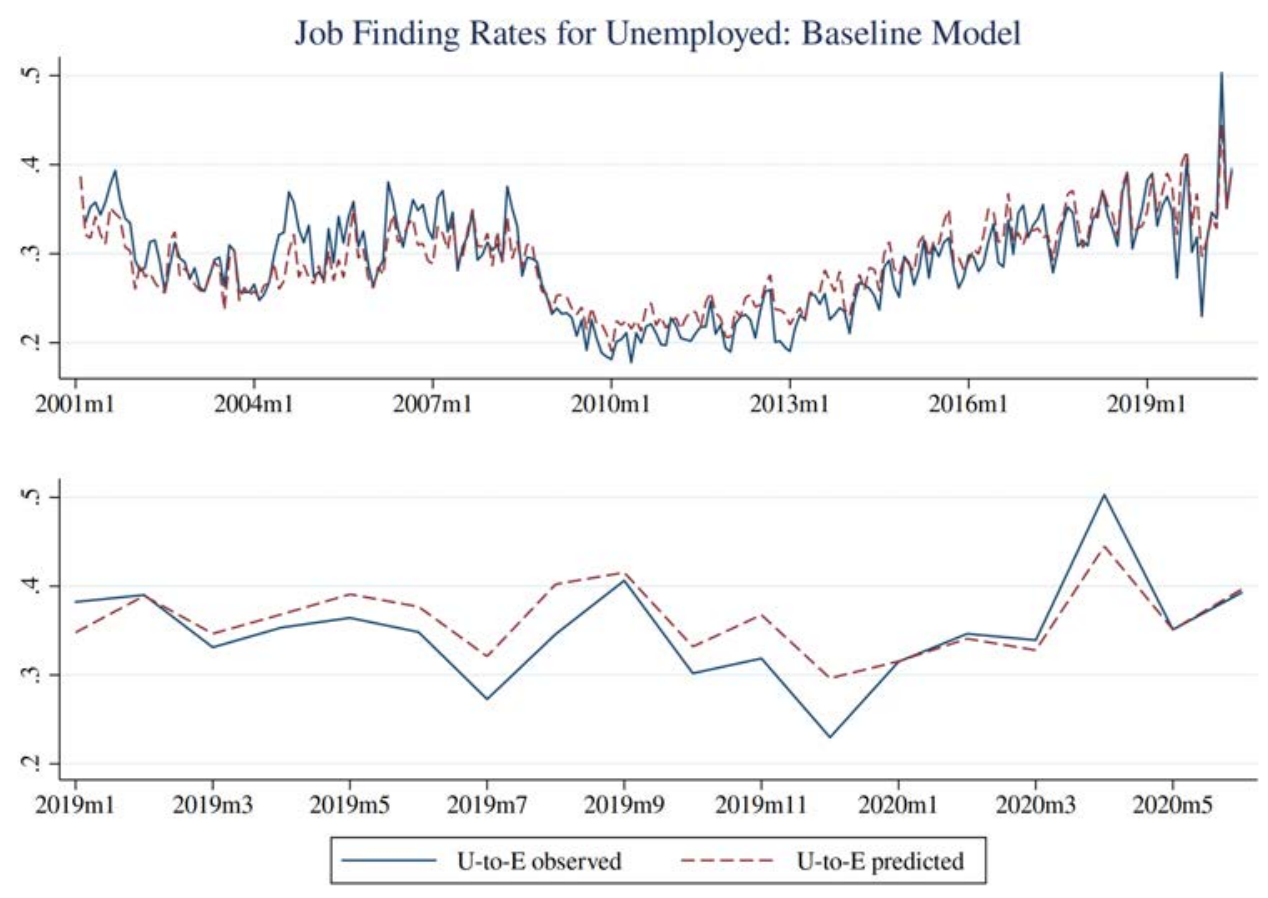

Notes: This figure reports the model-generated predicted job finding rates for unemployed workers, where the predictions are based on model estimates calibrated to match the 2001-2019 time period. The overall job finding rate of the unemployed is calculated by taking a weighted average of the job finding rates of the temporary and permanent unemployed.

\section{III.E. Model Fit}

After the estimation and calibration, we assess the fit of the model by comparing the observed and predicted job finding rates both in-sample (through the entire pre-2020 sample period) as well as out-of-sample throughout the first half of 2020. This exercise confirms the results in Kroft et al. (2016) and Krueger et al. (2014) that this kind of search-and-matching model (accounting for non-participation and long-term unemployment) can do a good accounting for labor market dynamics during and after the Great Recession, and our results here show that the model continues to fit well all of the way up through the end of 2019.

The fact that the fit of the model is very good up through December 2019 is perhaps not surprising since the distinction between permanent and temporary unemployment is relatively unimportant in the pre-2020 period. However, the model also fits well in 2020 up through July. Figure 10 shows the in-sample and out-of-sample fit for all unemployed individuals, while Figure 11 shows the fit of the job finding rates separately for the permanent and temporary unemployed.

The good out-of-sample fit through July 2020 means that the model predicts job finding 
Figure 11: Further Assessing the In-sample and Out-of-Sample Fit of the Baseline Model Job Finding Rates for Permanent Unemployed: Baseline Model
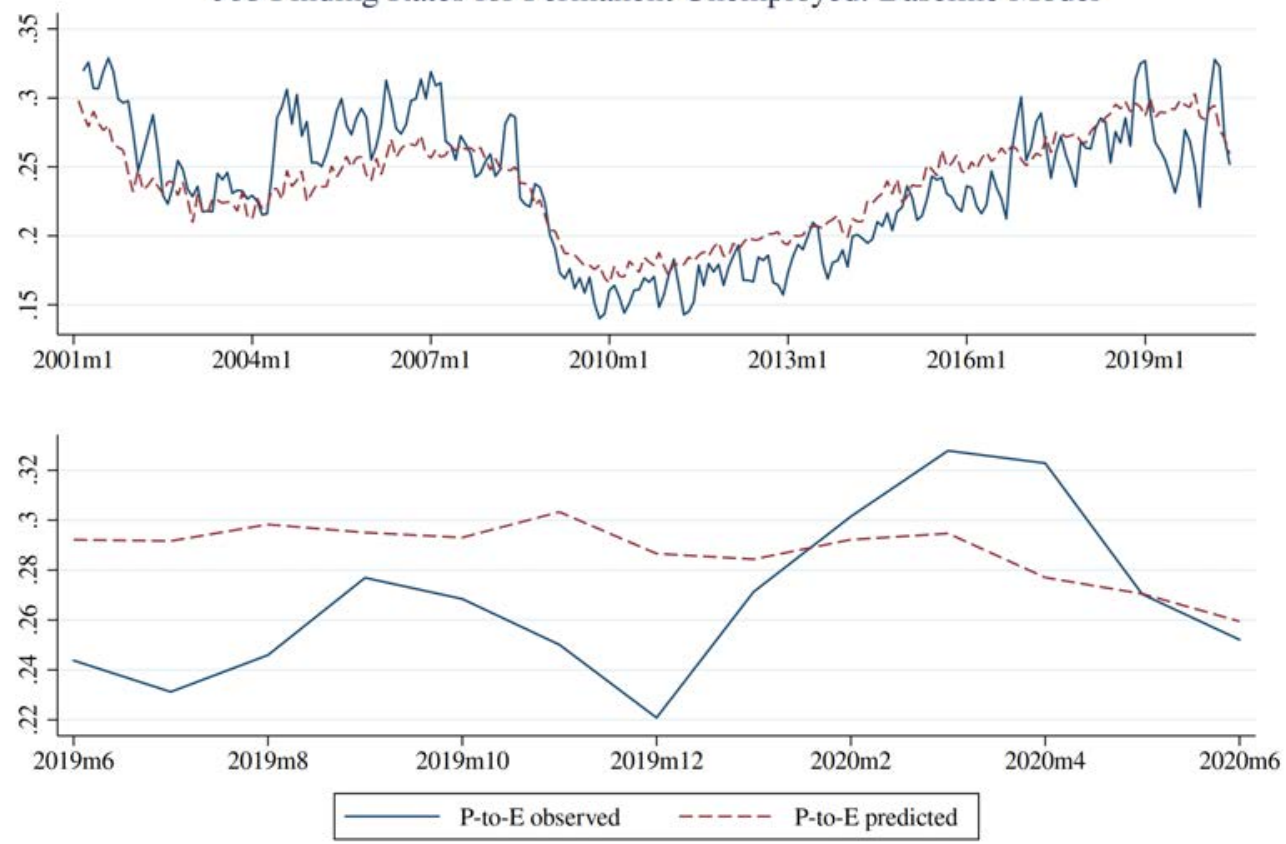

Job Finding Rates for Temporary Unemployed: Baseline Model
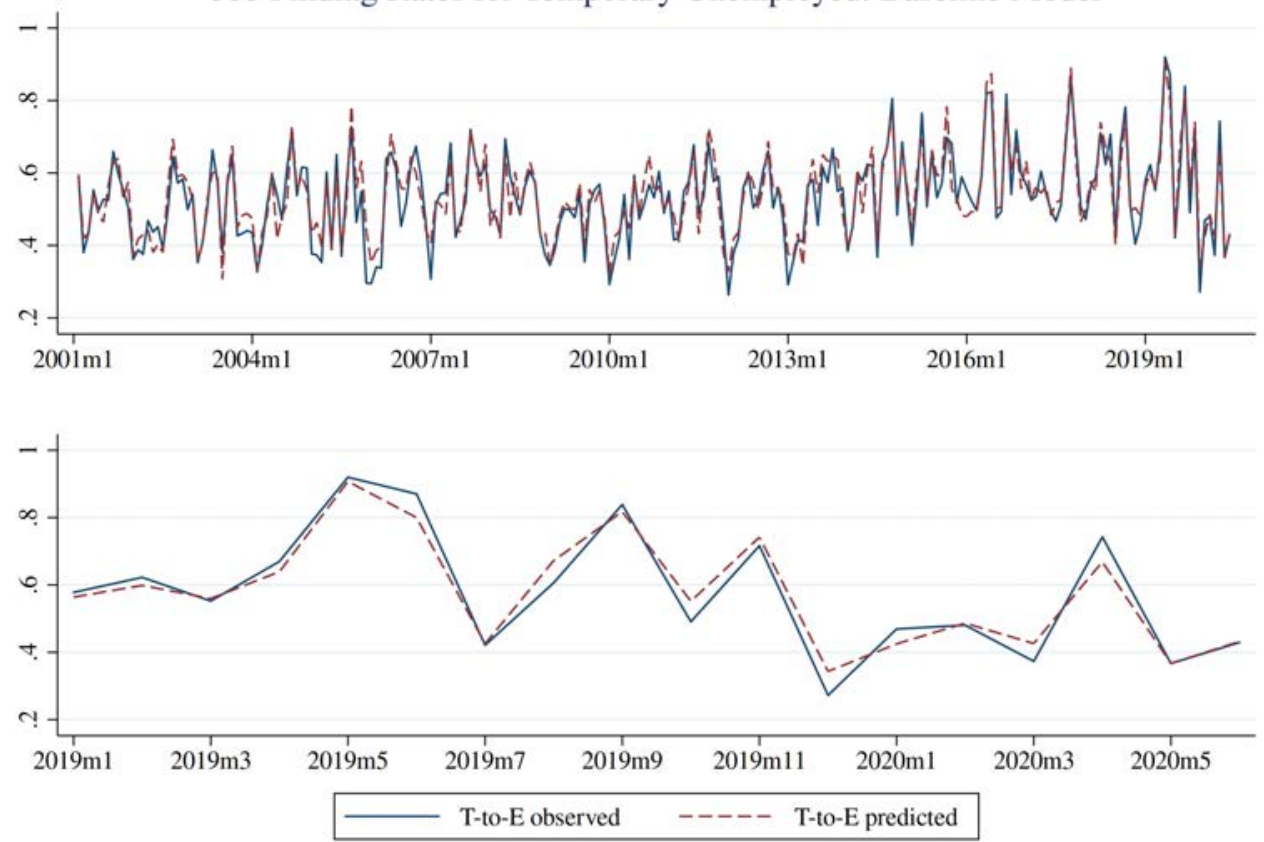

Notes: These figures report the model-generated predicted job finding rates for the permanent and temporary unemployed, where the predictions are based on model estimates calibrated to match the 2001-2019 time period. The predicted job-finding rate for the temporary unemployed is a weighted average of the job finding rate of the actively searching, which is predicted by the model, and the observed job finding rate of the waiting temporary unemployed. The observed job finding rate of the permanent unemployed is seasonally adjusted and smoothed by taking a 3 -month moving average. 
Figure 12: Calibrated Model Without Temporary Unemployment Has Poor Out-of-Sample Fit in 2020
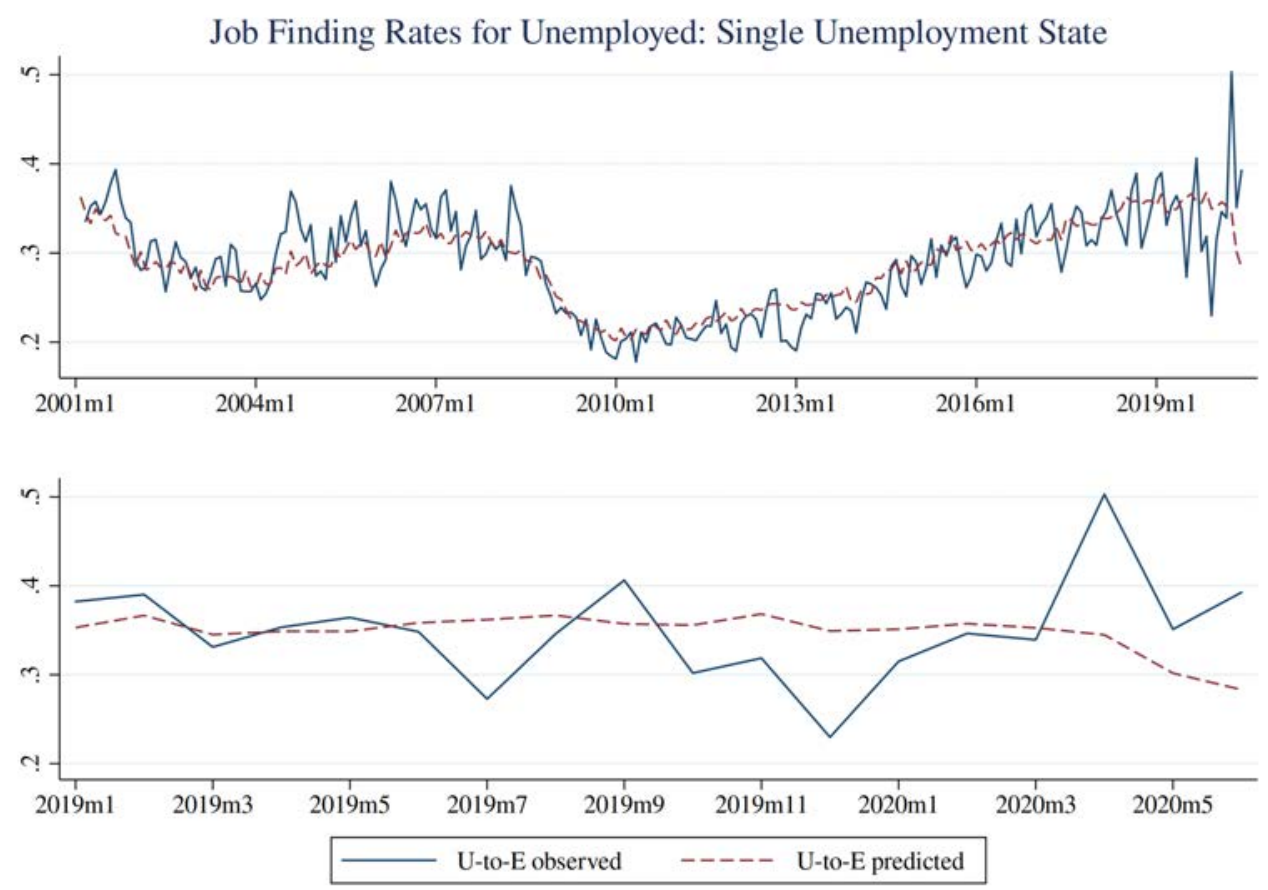

Notes: This figure reports the predicted job finding rates for unemployed workers generated by Kroft et al. (2016)'s model which does not distinguish between the temporary and permanent unemployed. The predictions are based on model estimates calibrated to match the 2001-2019 time period. 
rates very close to what we observe, and by comparing predictions to a model without temporary unemployment we can conclude that including temporary unemployed is key to the good outof-sample predictive power of the model. In particular, if we instead re-estimate the Kroft et al. (2016) model without distinguishing between temporary versus permanent unemployment, then we end up with similar parameters to what we would get using pre-2008 data (see column (2) of Table 2), but we would predict much lower job finding rates for the unemployed in 2020. Figure 11 shows that the model fits just as well in-sample, but breaks down in 2020. Strikingly, job finding rates for the unemployed increase in 2020 relative to the end of 2019, but the estimated model that does not distinguish between temporary and permanent unemployment would predict exactly the opposite - a steady drop in job finding rates following the surge in unemployment, as shown in Figure 12. ${ }^{25}$

Since the calibrated model appears to fit fairly well out-of-sample during the first several months of the COVID-19 recession, we use it to shed light on several economic phenomena. First, we use the model to understand movements in the Beveridge curve; second, we use the model to simulate changes in the unemployment rate through the end of 2021.

\section{Temporary Unemployment and the Beveridge Curve}

Our first use of the calibrated model is to understand movements along the Beveridge Curve at the start of the COVID-19 recession. Panel A of Figure 13 shows the dramatic movement of the Beveridge curve in recent months, with a substantial increase in unemployment without a correspondingly large decrease in job vacancies. ${ }^{26}$ Typically, during recessions, the Beveridge curve "loops around" counter-clockwise, with vacancies falling while unemployment rises, and then during the economic recovery unemployment falls and vacancies rise, but along a curve that appears to have "shifted outward" somewhat. Krueger et al. (2014) and Kroft et al. (2016) explain part of this apparent outward shift as resulting from duration dependence interacting with the historic increase in long-term unemployment during the Great Recession. In the language of the model above, total search effort was lower than would normally be indicated by the unemployment rate, since the share of unemployed who were long-term unemployed was very high.

\footnotetext{
${ }^{25}$ It also is perhaps apparent that the overall in-sample fit is better allowing for temporary unemployment, but this is unsurprising since there are more parameters and more forcing variables used. What is striking to us is that the trend in job finding rates is "wrong-signed" in 2020 in the Kroft et al. (2016) model without temporary unemployment.

${ }^{26}$ This matches the reduced form effort in Forsythe et al. (2020b) to adjust the Beveridge curve for searching unemployment by just relying on those they classify as being in the open market.
} 
Figure 13: Beveridge Curves

\section{Panel A: Vacancy/Unemployed Space}

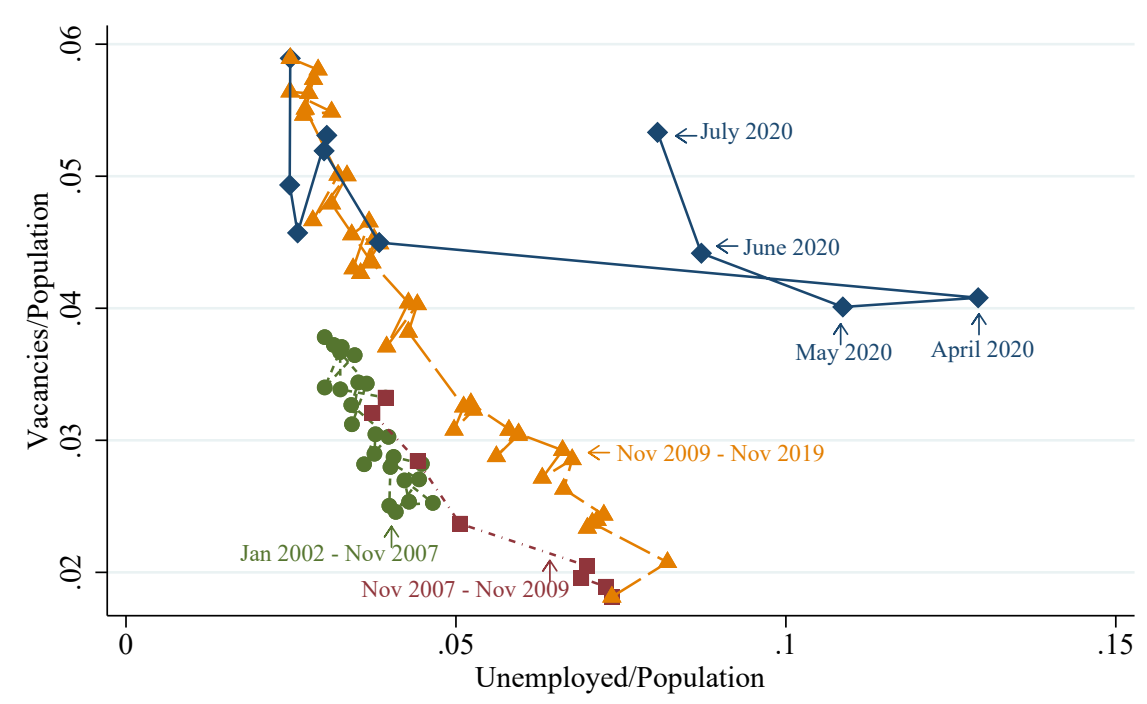

\begin{tabular}{|lll|}
\hline$-\cdots-\cdots$ & Jan 2002 - Nov 2007 & Nov 2007 - Nov 2009 \\
- & - N Nov 2009 - Nov 2019 \\
\hline
\end{tabular}

Panel B: Vacancy/Search Space

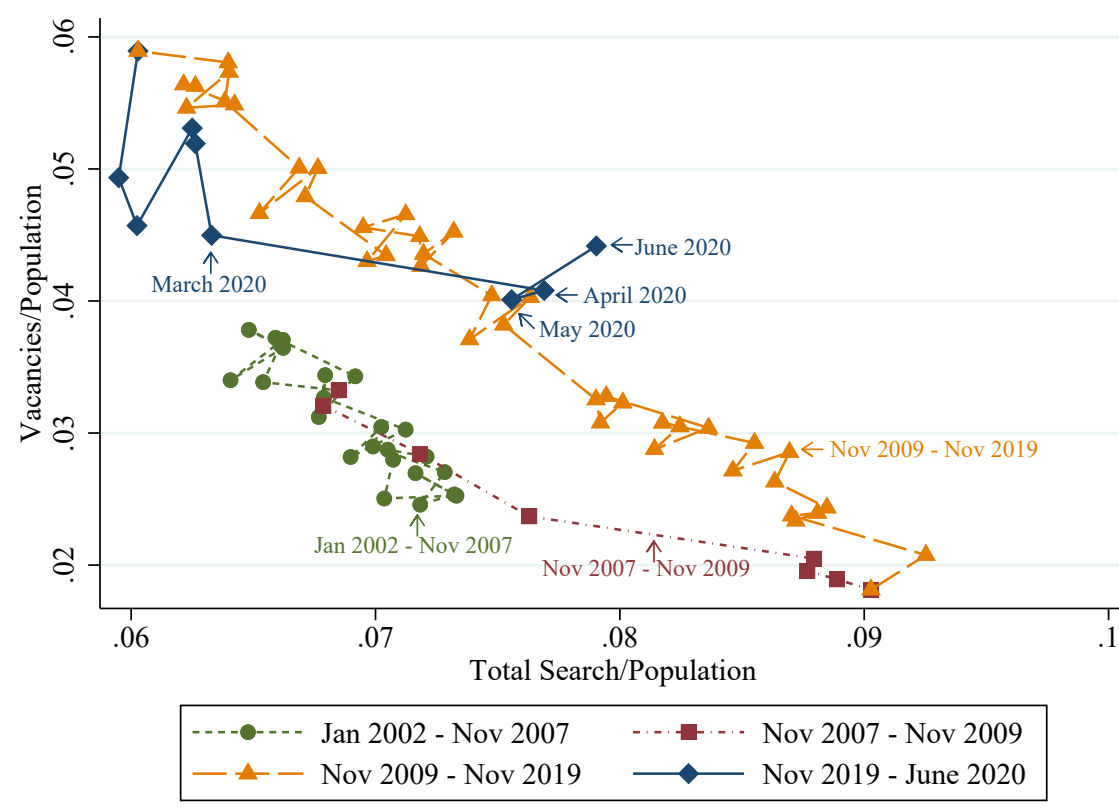

Notes: Panel A reports the Beveridge curve relationship between Vacancies and Unemployment, scaling both measures by the total prime-age adult population. Panel B adjusts for the composition of the Unemployed population using the calibrated model (normalizing each group relative to the search effort of a newly-unemployed worker). This measures market tightness as the ratio of vacancies to the total search effort $\left(V / S_{t}\right)$. Since temporary unemployment is very high in recent months and in the calibrated model the temporary unemployed search much less, this composition adjustment restores the shape of the Beveridge curve in recent months and leads to much less of an "outward shift" during the beginning of the COVID-19 recession. 
Since unemployment surged so quickly and vacancies did not collapse in the middle of 2020, the ratio of unemployed workers to vacancies reached roughly 3-4, similar to the ratio observed during the depths of the Great Recession. Such a high ratio of $U / V$ would usually indicate substantial labor market slack, with many unemployed workers competing over scarce vacancies. In this situation, additional search by newly-unemployed workers would normally create congestion in the matching process, which would lead to a reduction in job finding rates for everyone who is actively searching for a job.

This is in fact exactly what is predicted by the calibrated model that ignores the distinction between temporary and permanent unemployment, as discussed in the previous section. Without accounting for temporary unemployed in the pool of unemployed individuals, the model sees many newly-unemployed workers searching over a small number of vacancies, and this causes job finding rates to collapse (see Figure 12 above). But this is not observed during the middle of 2020; instead, overall job finding rates for the unemployed in May 2020 and June 2020 exceeded almost every other month during the entire 2001-2019 time period. We resolve this tension by distinguishing between the temporary unemployed (who are largely simply waiting to be recalled) and the permanent unemployed. Since the former are waiting and not searching, they do not affect the job finding rate in the search market. Thus, we can account for record numbers of unemployed with a fairly tight labor market and relatively high job finding rates for temporary unemployed workers who are actively searching.

What does this have to do with the Beveridge curve? In Panel B of Figure 13, we show a "search effort adjusted" Beveridge curve that scales each type of non-employed worker by their search effort relative to a newly-unemployed worker who has just been permanently laid off. This corresponds exactly to the $S_{t}$ term in the model described above. Quantitatively, this means that the contribution of the temporary unemployed to $S_{t}$ is "scaled down" since some of them are waiting to be recalled, just like the long-term unemployed on permanent layoff are "scaled down" because they also search less than newly-unemployed workers who have been permanently laid off.

The result of this is that when we calculate $S_{t}$ based on equation (7) (and normalize this by the population), the resulting Beveridge curve is much more well-behaved during 2020. In fact, there is now little evidence of any "outward shift," suggesting little change in matching efficiency or labor market tightness during the early months of the COVID-19 recession. In the Appendix, we show other versions of the Beveridge curve looking at just the temporary unemployed and the permanent unemployed, similar to how Krueger et al. (2014) report a Beveridge curve separately for the short-term and long-term unemployed. These figures support our interpretation that 
the temporary unemployed are key to understanding the apparently puzzling movements in the Beveridge curve in 2020.

We conclude that the large number of workers on temporary layoff at the start of the COVID19 recession lead to much less of a change in market tightness than if all of these workers had been permanently laid off. As workers on temporary layoff transition to permanent layoff, however, then our model predicts a greater contribution to market tightness, although the effect is still muted somewhat since both temporary unemployed and permanent unemployed experience negative duration dependence, and in our model we allow for (proportionally) similar duration dependence (as shown in Figure 8 above).

This analysis helps understand recent survey data from the Conference Board indicating that only 24 percent of workers say that jobs are hard to get (The Conference Board, 2020). This is much lower than the survey responses workers gave during the Great Recession, even though the official unemployment was higher in recent months than at any point during the Great Recession. In fact, the responses in recent months are fairly similar to 2015, when the unemployment rate was at 5.3 percent. This lines up fairly well with our adjusted Beveridge curve, with the most recent 2020 data points also hovering around the 2015 data points, once the unemployed have been properly scaled by their contribution to market tightness.

\section{Counterfactual Simulations}

We next use our calibrated model to forecast how the labor market will evolve in the next one to two years. Key to our counterfactual experiments will be the evolution of the forcing variables, which include the job separation rates, the job finding rates for the temporary unemployed waiting to be recalled, and the vacancy rate. The endogenous variables are the job finding rates for the permanent unemployed, the non-employed, and the temporary unemployed who are actively searching. These job finding rates feed back into the stocks of the unemployed of various types, and our model allows the unemployment duration distribution to evolve endogenously and dynamically.

The forcing variables in our model are determined by proximate causes which we treat as outside the scope of the paper. As an example, consider the recovery from a recession driven by a shortfall in demand. In such recoveries, the key driver is the path of demand: firms want to have enough workers to meet the demand for their products, and they adjust their layoffs, recalls, and vacancies appropriately.

It is possible that the dynamics in the labor market are entirely driven by these proximate 
causes and how they manifest themselves in the forcing variables of our model. For the latter to be true, the short-run dynamics would have to play out very quickly. However, our prior work (in Kroft et al. (2016)) and the work of Krueger et al. (2014) indicates that this is not always the case. In particular, we found that during the Great Recession, failure to account for the distribution of unemployment durations and duration dependence in job finding rates led to model predictions for the Beveridge Curve and long-term unemployment that perform significantly worse than a richer model that allowed for both duration dependence and movements in and out of the labor market. Given this prior work, we believe it is plausible a priori that search-and-matching frictions could be important factors in determining labor market dynamics during the COVID-19 recession, as well.

As a result, we consider two scenarios, both of which we consider to be pessimistic. Our "baseline" scenario assumes that it will take the forcing variables - evaluated at their June 2020 values - 24 months to linearly converge back to the pre-period rates, taken to be average rate of these forcing variables in the 12 months prior to March 2020 (March 2019 through February 2020). The second scenario is more pessimistic - imposing that the forcing variables remain at their June 2020 values indefinitely, meaning that there is no recovery in the vacancy rate or the separation rate over the next two years. Comparing these two scenarios informs whether a "stalling" of the recovery might lead to persistent scarring in the labor market.

Table 3 shows the values of the "forcing variables" for the 12-month pre-period as well each month since March 2020 (up to most recent data available). While $E$-to- $T$ rates have dropped from their peak level in April, they still remain elevated in June 2020 at a level 3-4 times higher than the pre-period. By contrast, the $E$-to- $P$ and $E$-to- $N$ rates have both returned to normal by June 2020. Most of the other forcing variables have returned to normal with the exception of the $N$-to- $T$ and $N$-to- $P$ rates which are higher than normal, the $P$-to- $T$ rate (which is also higher than normal), and the recall rate for the "waiting" temporary unemployed, which is somewhat lower than normal.

We start by examining the predictions of our ("baseline") scenario in Figure 14. This figure shows a steady reduction in the unemployment rate that is below professional forecasts. By December 2020, our model predicts an unemployment rate of 6.7 percent, which is below the available professional forecasts - the CBO (10.5\% in Q4) and the FED SEP Blue Chip (above 9\% in Q4). Academic and business economists surveyed by the Wall Street Journal expect the unemployment rate to be $8.1 \%$ by the end of 2020 (although the experts surveyed just one month earlier in August 2020 predicted an unemployment rate of $9 \%$ in December 2020). The figure also indicates that the baseline scenario continues to predict unemployment rate below 
Table 3: Forcing Variables Before and During the COVID-19 Recession

\begin{tabular}{|c|c|c|c|c|c|c|}
\hline Forcing variable & $\begin{array}{c}\text { Mar 2019 - } \\
\text { Feb 2020 } \\
\text { (Average) }\end{array}$ & Mar 2020 & Apr 2020 & May 2020 & Jun 2020 & Jul 2020 \\
\hline Vacancies & $7,108,250$ & $5,857,000$ & $5,305,000$ & $5,222,000$ & $5,843,000$ & $6,949,000$ \\
\hline $\mathrm{E}$ to $\mathrm{N}$ transition rate & 0.0229 & 0.0174 & 0.0527 & 0.0408 & 0.0237 & 0.0231 \\
\hline $\mathrm{E}$ to $\mathrm{T}$ transition rate & 0.0049 & 0.0208 & 0.1398 & 0.0374 & 0.0184 & 0.0191 \\
\hline $\mathrm{E}$ to $\mathrm{P}$ transition rate & 0.0057 & 0.0059 & 0.0100 & 0.0057 & 0.0066 & 0.0056 \\
\hline $\mathrm{T}$ to $\mathrm{P}$ transition rate & 0.1119 & 0.3724 & 0.1477 & 0.0342 & 0.0504 & 0.0389 \\
\hline $\mathrm{T}$ to $\mathrm{N}$ transition rate & 0.1806 & 0.5345 & 0.5708 & 0.1437 & 0.1287 & 0.1275 \\
\hline $\mathrm{P}$ to $\mathrm{N}$ transition rate & 0.4028 & 0.3712 & 0.6359 & 0.4186 & 0.3207 & 0.2289 \\
\hline $\mathrm{P}$ to $\mathrm{T}$ transition rate & 0.0167 & 0.0291 & 0.0881 & 0.0506 & 0.1213 & 0.1314 \\
\hline $\mathrm{N}$ to $\mathrm{P}$ transition rate & 0.0545 & 0.0482 & 0.0464 & 0.0474 & 0.0735 & 0.0511 \\
\hline $\mathrm{N}$ to $\mathrm{T}$ transition rate & 0.0036 & 0.0090 & 0.0321 & 0.0585 & 0.0467 & 0.0394 \\
\hline $\begin{array}{l}\text { Share of temporary } \\
\text { unemployed searching }\end{array}$ & 0.1808 & 0.1082 & 0.0832 & 0.1236 & 0.1942 & 0.2340 \\
\hline $\begin{array}{l}\text { Job finding rate of waiting } \\
\text { temporary unemployed }\end{array}$ & 0.6418 & 0.4555 & 0.8048 & 0.3728 & 0.4510 & 0.4163 \\
\hline
\end{tabular}

the forecasts throughout 2021.

We next consider the role of temporary unemployment by comparing the baseline model to the model in Kroft et al. (2016), which we call the "Single Unemployment State" model, since it does not distinguish between permanent and temporary unemployment. This model predicts a much higher unemployment rate over the next several months that is somewhat more in line with the professional forecasts. However, this model performs much worse in terms of its out-of-sample fit during the first half of 2020 , and this model would have already over-predicted unemployment each in June, July, and August 2020. This was clear from the previous section which showed that this model also substantially under-predicted the overall job finding rate of the unemployed.

Figure 15 presents our next comparison, which compares our baseline scenario to what we call the "indefinite stalling" scenario, where the forcing variables remain stuck at their June 2020 levels indefinitely. The main takeaway here is that the more pessimistic scenario projects values of unemployment that come closer overall to the CBO and the Fed SEP forecasts over the next 18 months. One interpretation is that, for the professional forecasts to be correct, the labor market has to "stall out" for an extended period of time, with continued high flows 
Figure 14: Comparing Forecasts Between Baseline Scenario and Model Without Temporary Unemployment

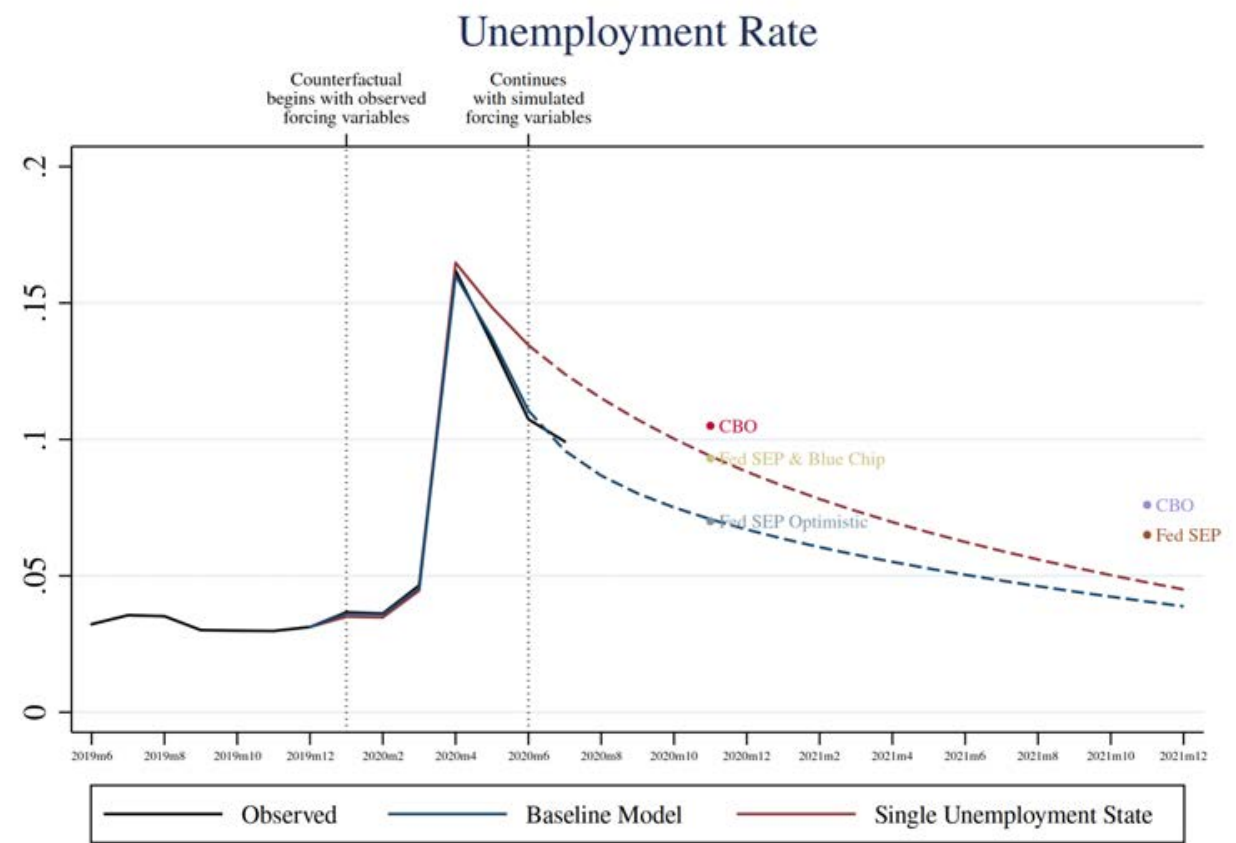

Notes: This figure reports the simulated unemployment rate from the baseline calibrated model and the Kroft et al. (2016) model ("Single Unemployment State") that does not distinguish between permanent and temporary unemployment. The CBO and Fed SEP (August 2020) forecasts of the unemployment rate in December 2020 and 2021 are presented for comparison.

Figure 15: Comparing Baseline Scenario to "Stalling Out" Scenario

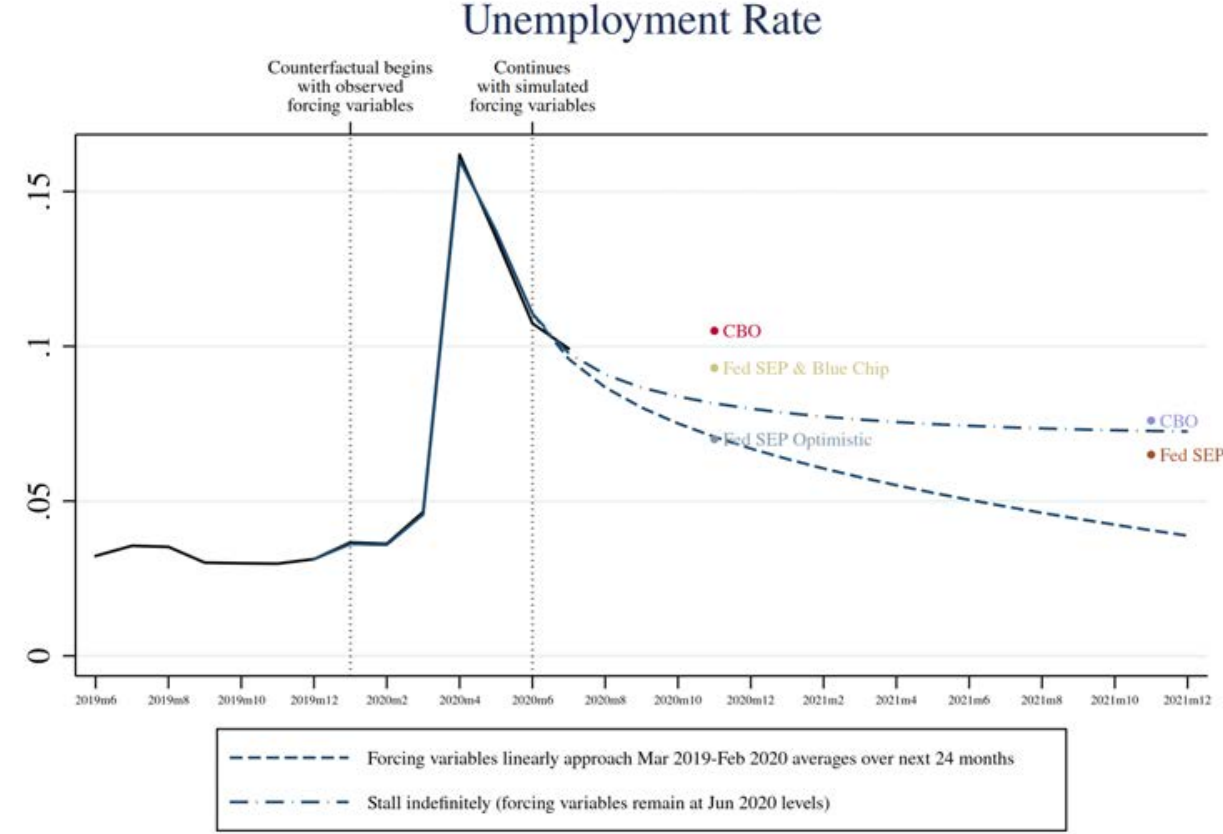

Notes: This figure reports the simulated unemployment rate from the baseline calibrated model under two different scenarios: a steady convergence and a "stalling out." The CBO and Fed SEP (August 2020) forecasts of the unemployment rate in December 2020 and 2021 are presented for comparison. 
from employment to temporary unemployment sustaining elevated unemployment rates, and labor demand remaining at below the pre-period levels. We believe this scenario to be quite pessimistic and unlikely, since the trend in the forcing variables between May and June has mostly been positive: separations into temporary unemployment have been falling and vacancies have been rebounding. Recall rates have not been increasing substantially, but they still remain quite high and close to pre-period average. Thus, for the CBO and FED SEP forecasts to be correct, our model implies that there must be a deterioration in labor demand - not just a slow convergence, but a "U-turn" in current trends in job separations and job vacancies, or a deterioration in the recall rates of the "waiting" temporary unemployed.

To further understand the labor dynamics of our calibrated model, Figure 16 decomposes the unemployment rate counterfactual into permanent and temporary unemployment. Starting with permanent unemployment, we see that the model fits quite well out-of-sample. The starting point for the two counterfactual series is $3 \%$ of the population in June 2020. This is about $40 \%$ higher than the rate observed in February 2020. What is striking about this figure is that under both scenarios the stock of permanent unemployment is projected to fall after reaching a peak in July 2020. In fact, one already notices a large change in the observed trend between June and July as this rate plateaus. This goes against the narrative that the COVID-19 recession will lead to an elevated stock of permanently unemployed workers. ${ }^{27}$ The reason for the drop comes in part from the fact that inflows into permanent unemployment while elevated in April 2020 - have largely reverted back to trend by June 2020. Additionally, even though the rate of vacancy posting has declined by about 20 percent relative to the preperiod, and we do not see much recovery in labor demand, the overall level of vacancies is still quite high - as high as 2015, for instance. Thus, outflows from unemployment to employment have continued to remain fairly high. According to our model, as long as overall labor demand holds up at the currently observed levels, the stock of the permanent unemployed will decline to something relatively close to the pre-period levels in the next 12 months. $^{28}$

Turning next to temporary unemployment, Figure 16 shows that since April 2020 there has been a pronounced drop in the temporary unemployment rate. This has been mostly responsible

\footnotetext{
${ }^{27}$ For example, Justin Wolfers quoted Betsey Stevenson's congressional testimony on September 11, 2020 saying: "The big problem [is] the labor market has moved on from temporary furloughs to growing permanent job loss. That'll cause the recession to drag ... for years."

${ }^{28}$ The second reason why the stock of permanent unemployed is predicted to decline is because the transition rate from permanent to temporary unemployment is unusually elevated in recent months. As we have discussed above, it does seem as if the boundary between permanent unemployment and temporary unemployment is more fluid at this point, but we believe that this is unlikely to continue as the flow into temporary unemployment declines.
} 
Figure 16: Decomposing Unemployment Rate Forecasts
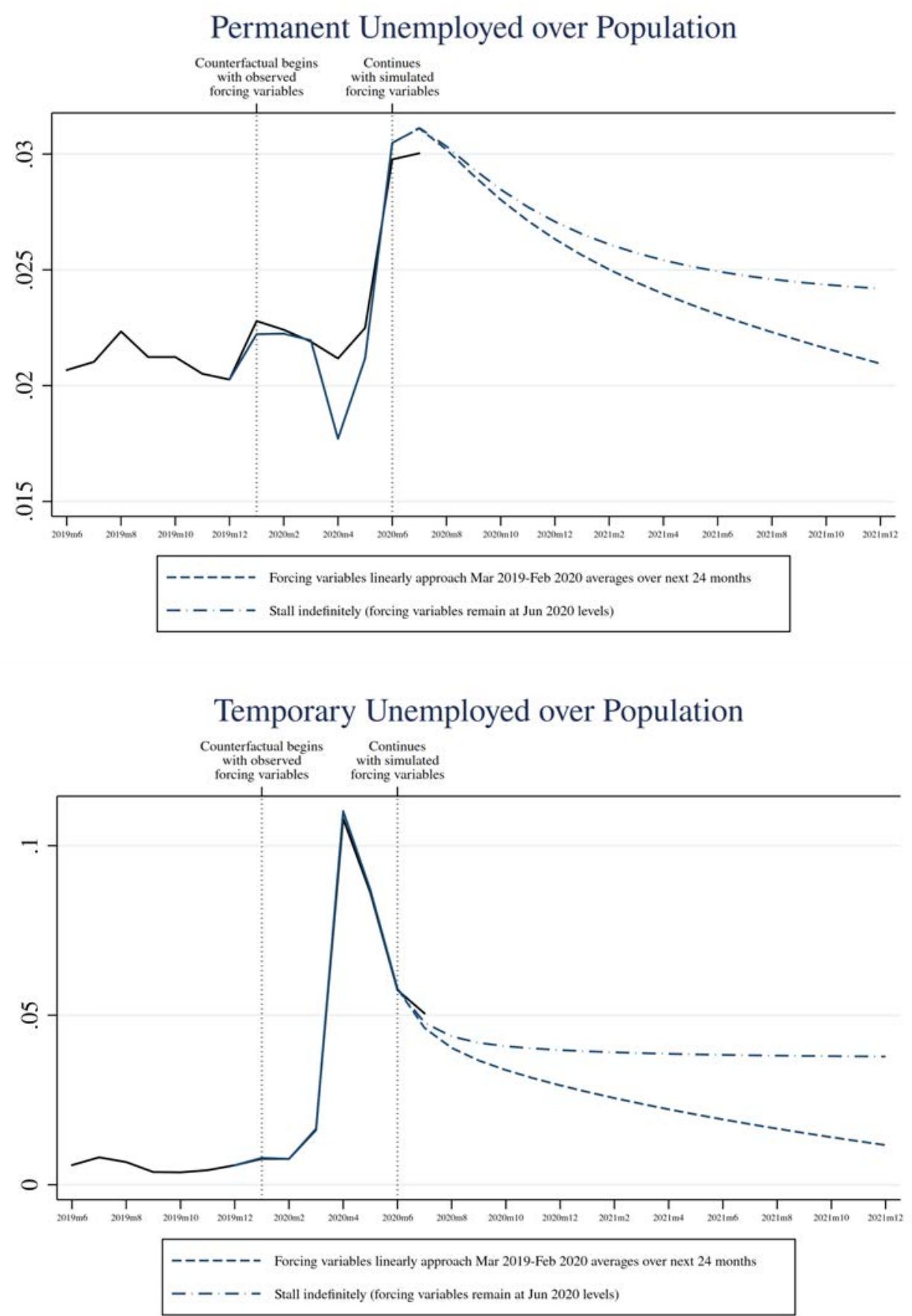

Notes: This figure reports the simulated Unemployment/Population ratios for the permanent and temporary unemployed from the baseline calibrated model under two different scenarios: a steady convergence and a "stalling out." The CBO and Fed SEP (August 2020) forecasts of the unemployment rate in December 2020 and 2021 are presented for comparison. 
for the observed drop in the overall unemployment rate. Our projections indicate that this rate will continue to drop, though much more slowly for the more pessimistic scenario. The reason for the rapid drop in the temporary unemployment rate is that temporary unemployment, as its label indicates, is very much a transient state with monthly job finding rates at or above 50 percent. Even though the recall rate has declined somewhat during the pandemic, it remains high. This is perhaps a bit surprising as one might have expected the number of business closures during the pandemic to affect recall rates. Moreover, it also to some extent explains why we do not predict a "building up" of the stock of permanent unemployment through $T$ to- $P$ transitions. Since recall rates have remained quite high, we do not see an elevated risk that individuals will transition from temporary to permanent unemployment. In fact, looking at Table 3, $T$-to- $P$ rates in June 2020 are actually lower than their normal (pre-2020) values. ${ }^{29}$

While our baseline scenario is more optimistic than prominent existing forecasts, it is worth cautioning against this optimism for several reasons. It may indeed be the case that the labor market worsens and reverses its trend, and we explore this possibility in additional scenarios. The Appendix reports figures for all of these scenarios, and here will summarize the conclusions for the unemployment rate forecasts. One reason the labor market could change course could be, for example, if the COVID-19 recession stimulus policies - such as the Paycheck Protection Program, or the Unemployment Insurance supplemental payments - were keeping labor demand "propped up" during mid-2020, and so the end of these programs could lead to a sharp drop in labor demand.

We first consider a scenario where labor demand - as proxied by vacancies and recall rates for the temporarily unemployed - decreases by 50 percent (relative to June 2020 values) during the second half of 2020 and then "stalls out" at these depressed levels for the next 12 months. Compared to our baseline model, we see higher unemployment rates that are more in line with the FED SEP forecasts, although even in this extremely pessimistic case, the model projected rates still fall short of the $\mathrm{CBO}$ forecasts. We show in the Appendix that essentially all of the increase in unemployment is coming from the drop in recall rates, as opposed to the drop in job vacancies. The reason is that temporary workers dominate the unemployed pool and so the

\footnotetext{
${ }^{29}$ Our discussion here has focused on permanent and temporary unemployment, but our model is also able to predict trends in non-participation. In the Appendix (Figure A26), we report predictions for the nonparticipation rate, defined as the ratio of non-participants to the population. In both scenarios, we see that the model predicts a continuous drop in the share of nonparticipants; the decline, however, is more drastic in the more pessimistic scenario. The reason for this difference has to do with the elevated outflows from nonparticipation in June 2020. In particular, the rates of $N$-to- $T$ and $N$-to- $P$ flows are elevated. As a result, the scenario that holds these forcing variables for the next two years at their currently-elevated levels leads to a more rapid outflow from non-participation and thus lower non-participation rates.
} 
unemployment rate is much more sensitive to changes in labor demand for these workers than changes in labor demand for workers actively search for a job.

While the previous counterfactual focused on outflow rates driven by firm hiring, the next counterfactual focuses on separation rates. Here we consider the scenario where all job separations ( $E$-to- $N, E$-to- $P$, and $E$-to- $T$ ) increase by 50 percent over the next 6 months. In this case, we find a rise in unemployment that comes much closer to professional forecasts. This illustrates again that for the professional forecasts to be right, there has to be a substantial deterioration in labor market flows. We think this scenario is also fairly unlikely, since this increase in job separations would bring separation rates up to the levels that prevailed during the Great Recession.

Overall, the counterfactual scenarios we consider do not suggest a very strong tendency for the wave of job loss that occurred in March-June 2020 to generate a stock of permanent unemployed, and the Appendix also shows that we do not see a surge in long-term unemployment as was seen during the Great Recession (consistent with Chodorow-Reich and Coglianese (2020)). We know that other combinations of shocks can lead to the kind of hysteresis observed during the Great Recession (where negative duration dependence amplifies an initial adverse shock); by contrast, even if we allow for duration dependence and transitions from temporary to permanent unemployment, we still predict a fairly rapid reduction in the unemployment rate, which we believe is largely driven by the relatively strong labor demand that is still observed.

\section{Conclusion}

This paper develops a search-and-matching framework that prominently features temporary unemployment alongside permanent unemployment and distinguishes between short-term and long-term unemployment. We show that accounting for this heterogeneity among the unemployed is crucial for understanding the dynamics of the COVID-19 recession up to July 2020. Ignoring this heterogeneity will lead one to substantially overestimate unemployment.

We calibrate our extended search-and-matching model and use it to forecast unemployment under different assumptions on the path of the exogenous forcing variables. Our main result is that the model projects an unemployment rate that is much lower compared to a model that ignores the distinction between temporary and permanent unemployment and compared to existing professional forecasts. In particular, we find that even if we assume that it takes separation rates and vacancies two years to return to their pre-recession levels, unemployment rates are still projected to fall rapidly. 
What explains the difference between our model forecasts and the professional forecasts? One possibility is that the professional forecasts are based on the path of unemployment in historical recessions. As Elsby et al. (2010) show, recessions are normally characterized by an initial period when inflows into unemployment rise as the rate of separation increases. This is then followed by a period of reduced job finding rates as a result of lower labor demand and hence rising unemployment. The COVID-19 recession resembles the front end of this dynamic. Similar to past recessions, it began with a dramatic increase in inflow rates. Unlike past recessions, however, outflows from unemployment have remained fairly high. In part, this is due to a composition effect, as the higher outflow rates are driven by the relatively high rates of re-employment among the temporary unemployed. Additionally, labor demand as proxied by job vacancies is somewhat lower than before the start of the COVID-19 recession but remains elevated.

Our analysis shows that assuming that the unemployment outflow rate follows the dynamics of past recessions may cause one to overstate the severity of the COVID-19 recession. We conjecture that this is one of the main reasons behind the pessimistic forecasts. In fact, our findings indicate that in order for our model to rationalize the professional forecasts, it would have to be the case that either separation rates would further increase by more than 50 percent, or vacancies and recall rates would have to fall by more than 50 percent in the coming months. In other words, the labor market would need to be hit by another Great Recession, a scenario that strikes us as unlikely given current labor market trends.

We conclude that our model provides some rigorous support for measuring labor market slack taking into account the composition of the unemployed - in particular, accounting for the distinction between temporary and permanent unemployment (and the share of the temporary that are actively searching) and the distinction between short-term and long-term unemployment. We believe this adjusted measure of labor market slack provides more useful guidance to forecasters and policymakers, and our analysis leads to a more nuanced interpretation of recent labor market struggles. While it is tempting to draw inferences about the path of the labor market from aggregate statistics on the state of the labor market, our findings demonstrate the important role of unemployment heterogeneity. In the case of the COVID-19 recession, past recessions may not necessarily be the most reliable guide to the future. 


\section{References}

Ahn, Hie Joo and James D. Hamilton, "Measuring Labor-Force Participation and the Incidence and Duration of Unemployment," 2020. Unpublished Manuscript available at https://econweb.ucsd.edu/ jhamilto/AH2.pdf.

Barrero, Jose Maria, Nicholas Bloom, and Steven J Davis, "Covid-19 is also a reallocation shock," National Bureau of Economic Research Working Paper \#27137, 2020.

Bartik, Alexander W, Marianne Bertrand, Feng Li, Jesse Rothstein, and Unrath Matt, "Measuring the Labor Market at the Onset of the COVID-19 Crisis," Brookings Papers on Economic Activity, 2020.

Bartik, Alexander W., Zoe Cullen, Marianne Bertrand, Edward L Glaeser, Michael Luca, and Christopher Stanton, "How Are Small Businesses Adjusting to COVID-19? Early Evidence from a Survey," Proceedings of The National Academy of Sciences, 2020, 117 (30).

BLS, "Frequently asked questions: The impact of the coronavirus (COVID-19) pandemic on The Employment Situation for March 2020," Technical Report, Bureau of Labor Statistics 2020.

Chodorow-Reich, Gabriel and John Coglianese, "Projecting Unemployment Durations: a Factor-Flows Simulation Approach With Application to the COVID-19 Recession," National Bureau of Economic Research Working Paper \#27566, 2020.

Elsby, Michael W L, "Evaluating the Economic Significance of Downward Nominal Wage Rigidity," Journal of Monetary Economics, 2009, 56 (2), 154-169.

Elsby, Michael WL, Bart Hobijn, and Aysegul Sahin, "The labor market in the great recession," Brookings Papers on Economic Activity, 2010, pp. 1-70.

_, _, Ayşegül Şahin, Robert G Valletta, Betsey Stevenson, and Andrew Langan, "The Labor Market in the Great Recession-An Update to September 2011 [with Comment and Discussion]," Brookings Papers on Economic Activity, 2011, pp. 353-384.

Forsythe, Eliza, Lisa B Kahn, Fabian Lange, and David Wiczer, "Labor Demand in the time of COVID-19: Evidence from vacancy postings and UI claims," Journal of Public Economics, 2020, 189, 104238.

_ , Lisa B. Kahn, Fabian Lange, and David Wiczer, "Searching, Recalls, and Tightness: An Interim Report on the COVID Labor Market," Technical Report 2020.

Fujita, Shigeru and Giuseppe Moscarini, "Recall and unemployment," American Economic Review, 2017, 107 (12), 3875-3916.

Goolsbee, Austan and Chad Syverson, "Fear, Lockdown, and Diversion: Comparing Drivers of Pandemic Economic Decline 2020," National Bureau of Economics Research Working Paper \#27432, 2020.

Gregory, Victoria, Guido Menzio, and David G. Wiczer, "Pandemic Recession: L or VShaped?," National Bureau of Economic Research Working Paper \#27105, 2020. 
Jones, Stephen R. G. and W. Craig Riddell, "The Measurement of Unemployment: An Empirical Approach," Econometrica, 1999, 67, 147-162.

Katz, Lawrence F, "Layoffs, Recall and the Duration of Unemployment," National Bureau of Economic Research Working Paper \#1825, 1986.

Katz, Lawrence F. and Bruce D. Meyer, "Unemployment Insurance, Recall Expectations, and Unemployment Outcomes," The Quarterly Journal of Economics, 1990, 105 (4), 973-1002.

Kroft, Kory, Fabian Lange, Matthew J. Notowidigdo, and Lawrence F. Katz, "Long-Term Unemployment and the Great Recession: The Role of Composition, Duration Dependence, and Nonparticipation," Journal of Labor Economics, 2016, (S1), 7-54.

_, Matthew J. Notowidigdo Fabian Lange, and Matthew Tudball, "Long Time Out: Unemployment and Joblessness in Canada and the United States," Journal of Labor Economics, 2019, (S2), S355-397.

Krueger, Alan, Alexandre Mas, and Xiaotong Niu, "The Evolution of Rotation Group Bias: Will the Real Unemployment Rate Please Stand Up?," The Review of Economics and Statistics, 2017, 99 (2), 258-264.

Krueger, Alan B., Judd Cramer, and David Cho, "Are the Long-Term Unemployed on the Margins of the Labor Market?," Brookings Papers on Economic Activity, 2014, Spring 2014.

Lilien, David M, "The Cyclical Pattern of Temporary Layoffs in United States Manufacturing," The Review of Economics and Statistics, 1980, 62 (1), 24-31.

Nekoei, Arash and Andrea Weber, "Recall Expectations and Duration Dependence," American Economic Review, 2015, 105 (5), 142-146.

Rothstein, Jesse, "Unemployment Insurance and Job Search in the Great Recession," Brookings Papers on Economic Activity, 2011, 43, 143-213.

Shimer, Robert, "Reassessing the Ins and Outs of Unemployment," Review of Economic Dynamics, $2012,15,127-148$.

The Conference Board, "Consumer Confidence Survey," June 2020. https://conference-board. org/data/consumerconfidence.cfm. 